\title{
Kaolin Particle Film Affects Grapevine Berry Quality in cv. Meili in Humid Climate Conditions
}

\author{
Ying Wang, Tingting Xue, Xing Han, Lingxiao Guan, and Liang Zhang \\ College of Enology, Northwest A\&F University, Yangling, Shaanxi 712100, \\ China
}

\begin{abstract}
Hua Wang and Hua Li
College of Enology, Northwest A\&F University, Yangling, Shaanxi 712100, China; Engineering Research Center for Viti-Viniculture, National Forestry and Grassland Administration, Yangling, Shaanxi 712100, China; Shaanxi Engineering Research Center for Viti-Viniculture, Yangling, Shaanxi 712100, China; and China Wine Industry Technology Institute, Yinchuan, Ningxia 750000, China
\end{abstract}

Additional index words. anthocyanin, berry composition, Vitis vinifera, volatile compounds

\begin{abstract}
Kaolin particle film (KPF) is an aqueous formulation of chemically inert mineral particles that can be sprayed on the surface of crops to form a protective film, resulting in increased fruit yield and quality. In this work, the effects of kaolin-based, foliar reflectant particle film on grape composition and volatile compounds in 'Meili' (Vitis vinifera L.) grapes were investigated under different growth stages over two growing seasons. The 100-berry weight and titratable acid content were decreased, and the sugar and soluble solid contents were increased in grapes of plants treated with kaolin over 2 years. Compared with grapes from plants not sprayed with kaolin, the levels of total phenol, flavonoid, flavanol, tannin, and anthocyanins of grapes from plants treated with kaolin for 2 years were mostly increased. High-performance liquid chromatography (HPLC) analysis also revealed an increased content of monomeric anthocyanin and changed anthocyanin composition. However, there was little effect on the volatile compounds in the grapes. These results demonstrate that KPF can facilitate the accumulation of sugar and phenolics, thereby improving grape quality even in a humid climate.
\end{abstract}

Wine grapes are one of the important widely cultivated crops in China, with high nutritional benefits. The maturation and metabolite composition of wine grapes are important determinants of the overall quality of grapes and wine (Kontoudakis et al., 2011). Grape maturation is generally expressed as the ratio of the sugar content to the acid content. Polyphenols are important secondary metabolites and are found at the highest levels in grape skins and seeds (Canals et al.,

Received for publication 26 Aug. 2020. Accepted for publication 24 Sept. 2020.

Published online 6 November 2020.

This research was supported by a study on the geographical origin identification of the grape cultivar Meili by elemental analysis (2017NY-107) and research and demonstration of key technologies for high quality and efficient production of grapes (20181008000008).

We would like to thank the Research and Development Center of Biorational Pesticide for providing the kaolin particle film. We also thank Yiwan Zhou for providing many useful suggestions. H.W. and H.L. are the corresponding authors. E-mail: wanghua@nwsuaf.edu.cn or lihuawine@ nwafu.edu.cn.

This is an open access article distributed under the CC BY-NC-ND license (https://creativecommons. org/licenses/by-nc-nd/4.0/).
2005). Many kinds of phenols are present, including tannin, anthocyanin, and flavonol; and the concentrations of these phenols significantly affects the color and taste of grapes and wine (Seddon and Downey, 2010). Other secondary metabolites are volatile substances, which comprise grape aroma (Palomo et al., 2007) and contribute greatly to the quality of fruit and wine (RoubelakisAngelakis, 2009). There are many factors that can affect the concentration and composition of secondary metabolites in grapes, such as grapevine variety, viticultural practices, and environmental factors (Nicolosi et al., 2012). Additionally, cultivation management measures can be implemented to improve the quality of grapes.

In recent years, there has been significant interest in the development of particle film technology (PFT) (Glenn and Puterka, 2010). Kaolin is an aluminosilicate mineral $\left[\mathrm{Al}_{4} \mathrm{Si}_{4}\right.$ $\left.\mathrm{O}_{10}(\mathrm{OH})_{8}\right]$ particle, and this material is nonporous, non-swelling, chemically inert over a wide range of $\mathrm{pH}$, low-abrasive, fine-grained, and plate-shaped. Most particle films are based on kaolin (Glenn and Puterka, 2010). KPF can inhibit the adhesion and infection of pests and pathogens by forming a physical barrier rather than through chemical toxicity, making the development of resistance less likely (Ferrari et al., 2017; Sharma et al., 2015). Additionally, due to its light-reflective properties, KPF technology can reduce the stress caused by high temperature and excessive light in many fruit crops (Bernardo et al., 2017; Glenn et al., 2002) and improve fruit finish, photosynthesis, and grape yield and composition (Dinis et al., 2017, 2018; Glenn and Puterka, 2010), resulting in higher overall fruit quality. For example, kaolin treatment increased the soluble solid content in Viognier grapes by $11 \%$ (Shellie and Glenn, 2008). Application of KPF to grapes and canopy during berry development stimulated major secondary metabolism pathways associated with grape quality, promoting the biosynthesis of phenolics (Conde et al., 2016), especially anthocyanin (Shellie, 2015). KPF itself showed minimal effect on the aroma substances of Merlot grape (Song et al., 2012). However, most studies have been carried out under high-temperature and drought conditions, or the studies tested use of this film together with deficit irrigation. There are few reports of the application of KPF under humid conditions.

'Meili' (Vitis vinifera L.) is a recently developed wine grape cultivar that was selected through cross breeding in 1982 and was first registered by the Fruit Industry Bureau of Shaanxi Province in 2011. This cultivar offers high and stable yields and shows strong resistance to disease, especially Plasmopara viticola (Zhang et al., 2013). Because of these properties, 'Meili' can be cultivated in humid areas. However, the quality of this cultivar, especially color accumulation, is lower than that of other red grape varieties, suggesting that cultivation strategies may be needed to improve 'Meili' quality (Song et al., 2013).

The goal of this study was to test the ability of KPF treatment to improve the quality of the wine grape cultivar Meili. The ability of foliar reflective KPF to improve grape quality was assessed by measuring grape maturation and the levels of secondary metabolites such as phenols and volatile compounds during the growing season. The results of this work can be used to develop strategies for effective new cultivation management.

\section{Materials and Methods}

Grapevine field conditions and sampling. The field trial was conducted in an experimental vineyard of the Northwest Agriculture and Forestry University (NWAFU), located in Yangling of Shanxi Province (lat. $34^{\circ} \mathrm{N}$, long. $108^{\circ} \mathrm{E}$ ), China. This area has a semiarid continental monsoon climate, and the soil type is bauxite. Grape berry samples were collected from own-rooted vines of the wine grape cultivar Vitis vinifera Meili planted in 2013. Vine rows were oriented west-east, with vines spaced in $1.0-\times 2.5-\mathrm{m}$ rows. The vines were head-trained, and these were pruned to two buds per spur. Vines were managed without irrigation. The other viticultural practices were performed according to local standards. 
This study was carried out during the 2018 and 2019 growing season. Values of monthly precipitation (from April to September in 2018 and 2019) and mean maximum temperature (from April to September in 2018 and 2019) are shown in Fig. 1. During grape ripening, usually in August and September, precipitation values were higher in 2019 than in 2018. And the temperature of July and August were also higher in 2019 than 2018.

The trial used a completely randomized design, with two treatments and three replicates of 50 plants each. To avoid wind drift and edge effects, the treatments were arranged on three nonadjacent rows, separated by two rows each. Ten untreated plants separated the experimental units. The two treatments were as follows: 1) treatment with $6 \%(\mathrm{w} / \mathrm{v}) \mathrm{KPF} ; 2$ ) untreated controls. In 2018 , KPF was first sprayed using a backpack sprayer on the whole canopy and grape clusters on $20 \mathrm{July}$, at the late green phase and before veraison. In 2019, the first spray was carried out on 18 July. The selection of $6 \%$ KPF concentration was based on previous research (Shellie and King, 2013b). The first application contained $1.5 \mathrm{~mL} / \mathrm{L}$ nonionic surfactant (branched chain fatty alcohol alkoxylated surfactant, TERGITOL ${ }^{\mathrm{TM}}$; Dow, Midland, MI). Two applications were performed on the first day to ensure uniformity of the kaolin adhesion. During the growth season, KPF was subsequently sprayed on vines when there was $\approx 10 \%$ new growth or when the white coating on the leaf surface appeared faded, especially after rain.

We randomly collected 300 grapes from KPF-treated and untreated control plants for each replicate from different parts of grape- vines and different parts of clusters. Sampling included one cluster randomly from each vine with or without particle film, respectively, totally 50 clusters in each plot ( 25 clusters from each side of the canopy). Six berries (two berries from the upper, middle, and lower parts, respectively) were sampled from each chosen cluster. The first sample collection was performed 2 weeks after the first KPF treatment, and then samples were collected every week until harvest. Samples in 2018 were collected 3 Aug. (veraison, $30 \%$ of berries per cluster had developed color), 10 Aug. (late veraison, $90 \%$ of berries per cluster had developed color), 17 Aug. (mature), and 24 Aug. (harvest, fully mature). Samples in 2019 were collected 1 Aug. (veraison, $30 \%$ of berries per cluster had developed color), 8 Aug. (late veraison, $90 \%$ of berries per cluster had developed color), 15 Aug. (mature), and 19 Aug. (harvest, fully mature). For 2019, the last two sampling dates were less than a week apart due to heavy rain before harvest. Some grapes were analyzed immediately and physicochemical indexes were measured, including 100-berry weight, soluble solids (SS), reducing sugar (RS), and titratable acid (TA). The remaining berries were stored at $-80{ }^{\circ} \mathrm{C}$ until later analysis.

The physicochemical indexes of grape berries. A subsample of 50 grapes was randomly collected from different clusters of different vines and weighed to calculate the 100-berry weight. The grapes were then crushed to juice, and the juice total soluble solids (SS) were determined using a hand refractometer. Titrable acid $(\mathrm{TA}, \mathrm{g} / \mathrm{L})$ of grape juice was determined by titration with $0.05 \mathrm{~mol} / \mathrm{L} \mathrm{NaOH}$. The reducing sugar (RS,

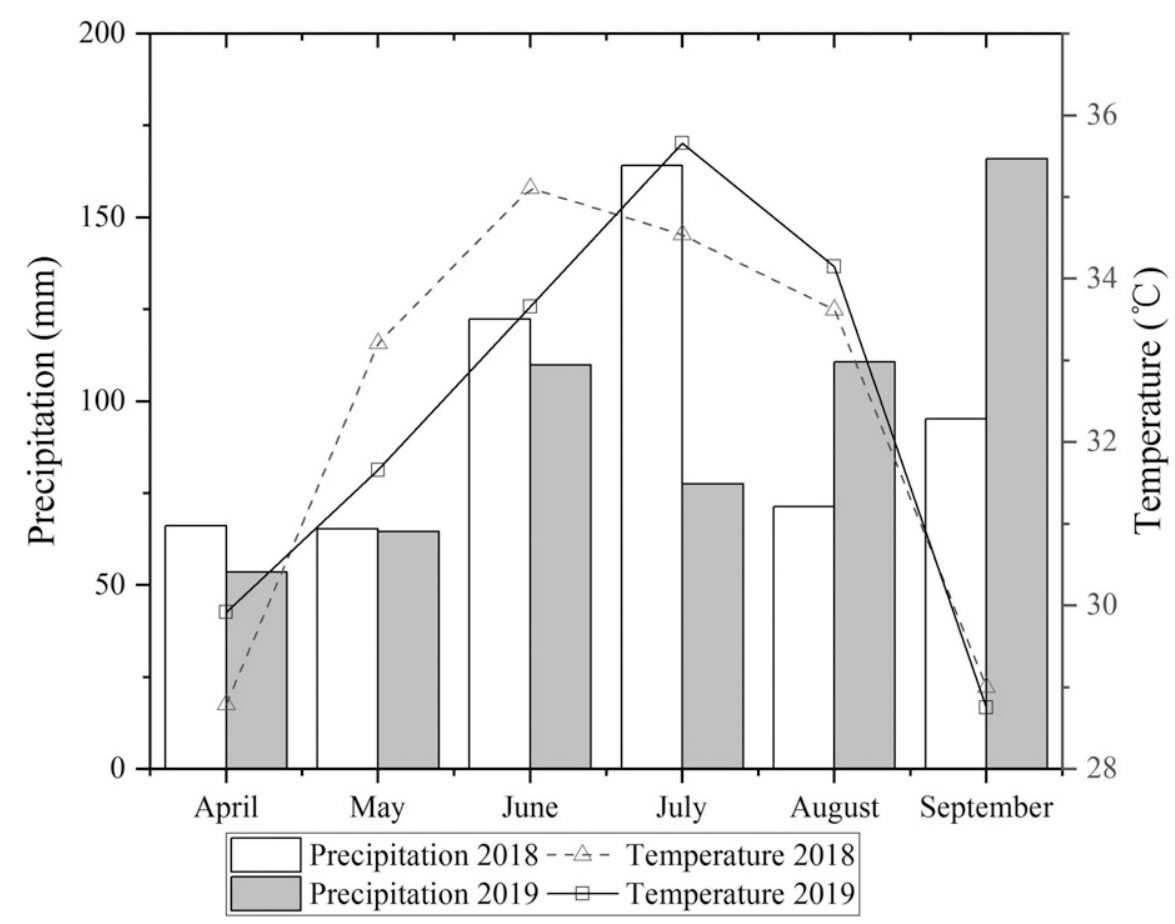

Fig. 1. Monthly precipitation and mean maximum temperature obtained during 2018 and 2019.

$\mathrm{g} / \mathrm{L})$ was analyzed according to the acid-base titration method (Shellie, 2006). All parameters were analyzed in triplicate.

Polyphenols content in grape berries. Polyphenol extraction from grapes was performed according to the method previously described by Xue et al. (2019) with some modifications. Briefly, 100 grapes from those stored at $-80{ }^{\circ} \mathrm{C}$ were randomly selected, the skins were peeled, and the seeds were removed. Liquid nitrogen was added into skins and seeds separately, and then the material was ground in a mortar to a fine powder. The powder was put in a freeze dryer (FD-1C-50) for $24 \mathrm{~h}$, and then transferred to a plastic pack and stored in a freezer at $-20{ }^{\circ} \mathrm{C}$. The phenolic constituents were then extracted with methanol- $\mathrm{HCl}(60 \%$ methanol, $0.1 \% \mathrm{HCl}$ ) and treated in an ultrasonic radiation machine using a ratio of $20 \mathrm{~mL}$ of solvent to $1 \mathrm{~g}$ of the sample at $30^{\circ} \mathrm{C}$ and $40 \mathrm{~W}$ for $30 \mathrm{~min}$. The liquid extracts were separated from the solids by centrifugation (Eppendorf AG 22331 Hamburg, Germany) in 10,000 rpm for $10 \mathrm{~min}$, and the supernatants were collected into glass bottles. All extractions were performed in triplicate, and the supernatants of three extractions were collected, pooled, and stored in a freezer at $-20{ }^{\circ} \mathrm{C}$. The above operations were performed with protection from light.

The total tannin content of the samples was determined by methyl cellulose precipitation (Sarneckis et al., 2010). The total flavanol content of the samples was determined using a p-DMACA-HCl method ( $\mathrm{Li}$ et al., 1996). The total flavonoid content of the samples was determined by spectrophotometric method (Marinova et al., 2005). The total phenol content in grapes was determined using a modified Folin-Ciocâlteu colorimetric method (Jayaprakasha et al., 2001). The anthocyanin content in grape skins was determined using the AOAC $\mathrm{pH}$ differential method (Lee et al., 2005). Phenolic substances were detected by spectrophotometer (Cary 60 ultraviolet-Vis; Agilent Technologies, Santa Clara, CA).

All measurements were determined three times, and all parameters were analyzed in triplicate.

HPLC analysis of monomeric anthocyanins in grape skins. Only monomeric anthocyanins of fully mature grapes (harvested 24 Aug. 2018) were analyzed. The extraction of anthocyanins from grape skins was performed as follows. The frozen powder prepared as described above was accurately weighed $(0.5000 \mathrm{~g})$ and then suspended in $10 \mathrm{~mL}$ of methyl alcohol. The resulting suspension was ultrasonicated $\left(<28{ }^{\circ} \mathrm{C}\right)$ for $10 \mathrm{~min}$ in darkness, shaken in darkness for $30 \mathrm{~min}$, and centrifuged at $12,000 \mathrm{~g}$ for $5 \mathrm{~min}$, and then the supernatant was collected. The precipitate was re-extracted with methyl alcohol $(10 \mathrm{~mL})$ three times, and the supernatants were pooled and concentrated using a CentriVap Concentrator (Labconco, Kansas, MO). The residue was dissolved with $10 \mathrm{~mL}$ mobile-phase solvent (solvent A:B = 9:1, described below), and the suspension was passed through a $0.45-\mu \mathrm{m}$ polypropylene syringe filter (Jinteng, Tianjin, China) for quantitative HPLC analysis. 
Anthocyanin analysis was performed using an Agilent 1100 Series LC/MSD (Agilent), reverse-phase column (Kromasil 1005C18, 250-×4.6-mm i.d., $5 \mu \mathrm{m}$; Restek Co., Bellefonte, PA). The mobile phase was comprised of solvent A (water/formic acid/acetonitrile, 92:2:6, v/v/v) and solvent B (water/ formic acid/acetonitrile, 44:2:54, v/v/v), and the following gradient was applied: 1$18 \mathrm{~min}, 10 \%$ to $25 \% \mathrm{~B}$; $18-20 \mathrm{~min}, 25 \% \mathrm{~B}$; $20-30 \mathrm{~min}, 25 \%$ to $40 \% \mathrm{~B} ; 30-35 \mathrm{~min}, 40 \%$ to $70 \% \mathrm{~B} ; 35-40 \mathrm{~min}, 70 \%$ to $100 \% \mathrm{~B}$. The column temperature was $50{ }^{\circ} \mathrm{C}$, and the flow rate was $1.0 \mathrm{~mL} \cdot \mathrm{min}^{-1}$. The injection volume was $30 \mu \mathrm{L}$. The anthocyanin content was detected at $525 \mathrm{~nm}$. Quantitative determination was carried out by comparison with an external standard method of malvidin-3-Oglucoside.

The analysis of volatile compounds in grapes. Free volatile compounds were analyzed using headspace-solid phase micro extraction-gas chromatography with mass spectrometry (HS-SPME-GC-MS).

Randomly selected whole grape samples $(\approx 100 \mathrm{~g})$ frozen at $-80{ }^{\circ} \mathrm{C}$ were ground in a mortar under liquid nitrogen to a fine power. The seeds were removed before grinding. Crosslinked polyvinylpyrrolidone (PVPP) was added to the obtained powder. The mixture then macerated in the dark for $2.5 \mathrm{~h}$ at $25^{\circ} \mathrm{C}$, centrifuged at $10,000 \mathrm{rpm}$ for $20 \mathrm{~min}$, and the resulting supernatant was used for volatile analysis. Before HS-SPME-GC-MS analysis, $5 \mathrm{~mL}$ of extracted juice and $1.5 \mathrm{~g}$ $\mathrm{NaCl}$ were added to each SPME vial containing $10 \mu \mathrm{L}$ of the internal standard solution $(0.230 \mathrm{~g} / \mathrm{L}$ 2-Octanol).

HS-SPME-GC-MS analyses were performed using a GCMS-QP2010 Ultra (Shimadzu, Japan). Compounds were separated with a DB-Wax column $(30-\mathrm{m} \times 0.25-\mathrm{mm}$ i.d., $0.25-\mu \mathrm{m}$ film thickness, Agilent). The oven temperature was programmed at $40{ }^{\circ} \mathrm{C}$ for 4 min of holding and increased to $120^{\circ} \mathrm{C}$ at a rate of $4{ }^{\circ} \mathrm{C} / \mathrm{min}$, increased to $240{ }^{\circ} \mathrm{C}$ at a rate of $6^{\circ} \mathrm{C} / \mathrm{min}$, and then held for $11 \mathrm{~min}$. A constant helium flow of $17 \mathrm{~mL} / \mathrm{min}$ was used. A column splitter was used at the end of the column, so that a $1 \mathrm{~mL} / \mathrm{min}$ column flow was introduced to the mass spectrometry, and the other $1.5 \mathrm{~mL} / \mathrm{min}$ flow was vented out. The ion source temperature was $230^{\circ} \mathrm{C}$. Electron impact mass spectrometric data were collected from $\mathrm{m} / \mathrm{z} 35-350$, with an ionization voltage of $70 \mathrm{eV}$.

Qualitative analysis of the aroma was performed by comparing the retention times and the mass spectra of the samples with those of available standards and those available in the NIST 14 mass spectrometry database included in the GC-MS analysis software (GCMS solution Version 4.30). The concentrations of volatile compounds in samples were calculated by comparison with 2-octanol as an internal standard. Odor activity values (OAVs) were calculated by the ratio of concentration to the odor threshold value of the compound, and an average OAV was determined as the average of four samples.
Statistical analysis. Statistical analyses were conducted with SPSS 19.0 software. Data were averaged by treatment, and treatments were compared using the Student's $t$ test. As presented in the figures, for each condition, the level of statistical significance of the differences between mean values is indicated with asterisk notation, where * corresponds to $P<0.05$ and ** corresponds to $P<0.01$. Volatile compounds with an average OAV $>1$ were analyzed by principal component analysis (PCA), using Origin 2018 software.

\section{Results}

Maturation of grape berries. Figures 2 and 3 show the effects of spaying KPF on the physicochemical indexes of grape berries after veraison in 2018 and 2019, respectively. The 100-berry weight increased from veraison to maturation in 2018 , but it decreased in 2019. Soluble solids (SS) and reducing sugar increased from veraison to maturation, while the titratable acid (TA) contents decreased in both years. On four sampling dates, grapes treated with kaolin had lower 100-berry weight than grapes from plants that did not receive KPF treatment. This increase was significant in 2018 (Fig. 2A), but not in 2019 (Fig. 3A). The SS and reducing sugar contents in grape berries were higher in 2018 than in 2019; and they were also higher for plants that received the KPF treatment compared with control plants (Figs. $2 \mathrm{~B}$ and $\mathrm{C}$ and $3 \mathrm{~B}$ and $\mathrm{C}$ ). Compared with control plants, grapes from plants treated with KPF had a lower TA content on three out of four sampling dates (Fig. 2D) in 2018. In 2019, the TA content was also significantly decreased by KPF treatment, except for grapes collected on 8 Aug. (Fig. 3D).

Content of phenols of grape berries. The effect of KPF treatment on the phenol content in grape skins was determined for grapes collected on different dates, and the results are shown in Figs. 4 and 5. In KPF-treated plants in 2018, the total phenolic content in grape skins first decreased (3 and 10 Aug.) and then increased (24 Aug.) from veraison to maturation, except in grapes collected 17 Aug., which showed no significant difference to the levels in grapes from untreated plants. Application of KPF also increased total phenols in grape skins on three out of four sampling dates in 2019 (Fig. 5A). The overall increase was $24.71 \%$ (from 22.86 to 28.50 $\mathrm{mg} / \mathrm{g}$ ) in 2019 , but only $5.04 \%$ (from 41.96 to $44.07 \mathrm{mg} / \mathrm{g}$ ) in 2018 . However, the overall total phenol content in grape skins was higher in 2018 than 2019. In 2018, the content of flavonoids in grape skins was also increased by KPF treatment on three out of four sampling dates, with a decrease on the second sampling date (Fig. 4B), for a total increase of $28.85 \%$ (from 51.67 to $66.58 \mathrm{mg} / \mathrm{g}$ ) over the season. A similar influence of KPF on flavonoids in grape skin was observed in 2019. Grapes from KPF-treated plants had higher flavonoids in the skin at harvest than grapes from plants that did not receive this treatment
(Fig. 5B). The total increase of flavonoids by harvest in 2019 was $19.10 \%$ (from 33.58 to $44.01 \mathrm{mg} / \mathrm{g}$ ). A decreasing trend was observed for flavanol content in grape skin, with KPF treatment decreasing flavanol content in grape skin on all sampling dates during the maturation process in 2018 (Fig. 4C). Interestingly, the opposite effect on grape skin flavanols was seen for KPF treatment in 2019, where there was an increase in grapes from plants that received kaolin treatment on two out of four sampling dates, but no significant difference at harvest (Fig. 5C). For 2018, grapes from treated plants had a lower tannin content in the skins at some time points, but there was no difference in grapes at harvest (Fig. 4D). In 2019, the tannin content in grape skins was increased by $10.68 \%$ by KPF treatment (Fig. 5D; from 33.46 to $37.04 \mathrm{mg} / \mathrm{g}$ ). The anthocyanin content in grape skins increased from veraison to harvest, and KPF treatment significantly increased the anthocyanin content for both years (Figs. 4E and 5E). Anthocyanin increased by $48.15 \%$ (from 4.65 to $6.89 \mathrm{mg} / \mathrm{g}$ ) in 2019 and $35.11 \%$ (from 6.64 to $8.97 \mathrm{mg} / \mathrm{g}$ ) in 2018 over the season.

The ratio of anthocyanins to soluble solids (A/SS) was also analyzed, and the results are shown in Tables 1 and 2. Compared with the control, the A/SS was increased by KPF treatment on three out of four sampling dates, except for the first sampling date (3 Aug.) in 2018. A similar trend was observed for 2019.

The effect of KPF treatment on the content of phenols in grape seeds is shown in Figs. 6 and 7. The changes of seed total phenol and flavonoids induced by KPF treatment were like the changes observed in the grape skins for the two years. KPF treatment increased the total phenol and flavonoid to varying degrees, and the changes of seed flavanols were consistent for the two years. Grape seeds from plants treated with KPF had a higher flavanol content and lower tannin content in both years.

Monomeric anthocyanin in grape skin. Table 3 shows the monomeric anthocyanin content of grapes from control and KPFtreated plants when the grapes were nearly mature (24 Aug.) in 2018. For grapes from both control and KPF-treated plants, acylated anthocyanins were not detected by HPLC analysis. Total monomeric anthocyanin was increased by KPF treatment, and all detectable kinds of monomeric anthocyanin were higher in grapes from KPF-treated plants compared with control plants.

We further analyzed changes in anthocyanin composition. Two types of anthocyanin were measured, as shown in Table 3. Delphinidin and derivatives, which confer blue color, exhibited greater increases than cyanidin and derivatives $(38.30 \%$ and $34.38 \%$, respectively). In plants subjected to KPF treatment, the observed change in the level of low-methylated anthocyanins, which are more sensitive to high temperature, was greater than the change in the level of highmethylated anthocyanidins $(39.15 \%$ and $33.51 \%$, respectively). 
A

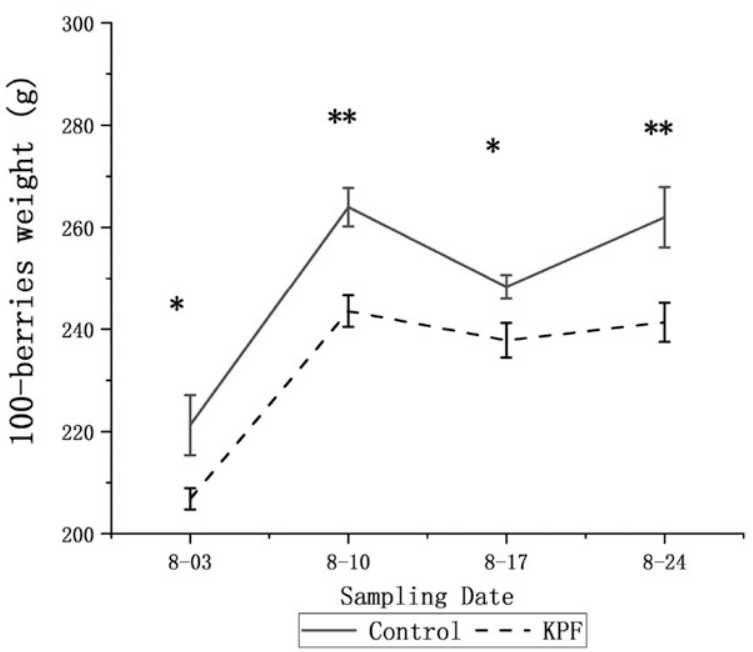

$\mathrm{C}$

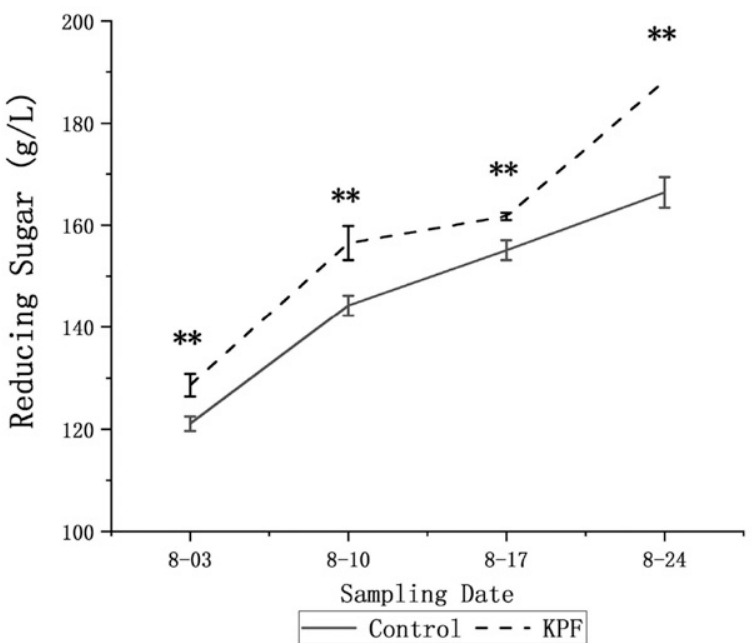

B

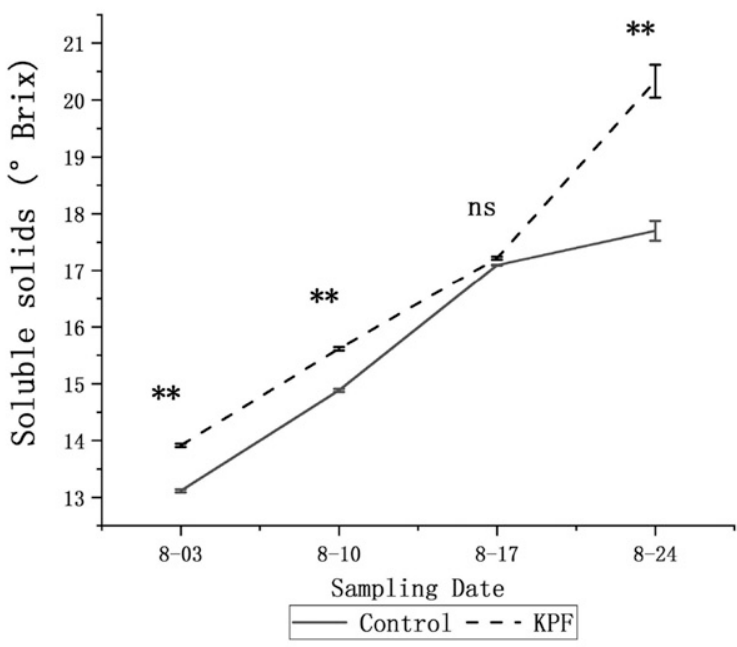

$\mathrm{D}$

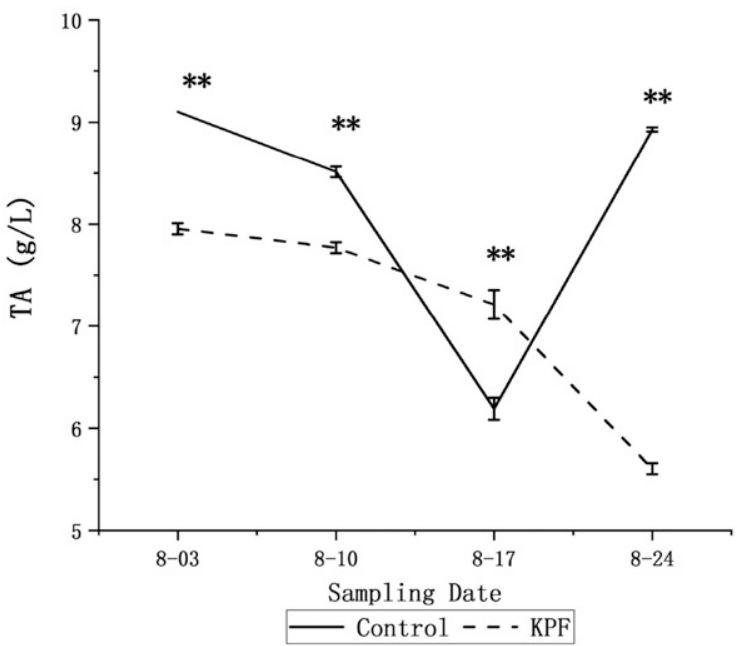

Fig. 2. Effect of kaolin application on the physicochemical indexes of grape berries in 2018. The effect of exogenous kaolin on (A) 100-berries weight, (B) soluble solids (SS), (C) reducing sugar, and (D) titratable acid (TA). Grape berries were collected on five different dates after veraison from vines treated with kaolin particle film (KPF) and without KPF application (control). Values are the mean \pm SEM of four independent experiments. Effects of kaolin were tested by Student's $t$ test. ${ }^{*} P<0.05$ and ${ }^{* *} P<0.01$ represent significant differences between treatments (control and KPF) and NS indicates not significant.

Volatile compounds. Important volatile compounds were quantified in mature 'Meili' grapes harvested from plants treated or not treated with KPF, and the results are presented in Table 4. Forty-five volatiles were detected and classified into seven categories based on chemical structure. The analysis included seven higher alcohols, fifteen volatile benzene derivatives, seven aldehydes, four ketones, one terpene, ten esters, and azulene. In 2018, the content of various volatile components was significantly influenced by KPF treatment, but less obvious changes were detected for grapes harvested in 2019.

The OAV for each compound was calculated as the ratio of the concentration to the sensory threshold value of the compound, and average OAVs were calculated from the values of four samples. The odor threshold values were taken from previous literature, as listed in Table 4 (Buttery et al., 1988; Fan et al., 2010; Guth, 1997b; La Guerche et al., 2006; Li, 2006; Moreno et al., 2005; Peinado et al., 2004). The concentrations of 16 out of 45 volatile components were higher than their corresponding threshold values $(\mathrm{OAV}>1)$ : 3 hexen-1-ol, 1-octen-3-ol, benzeneacetaldehyde, methyl salicylate, 2,4-di-tert-butylphenol, 2methyl-1-butanal, hexanal, octanal, nonanal, decanal, 2-octanone, 2-nonanone, methyl 2methoxybenzoate, ethyl octoate, ethyl caprate, and (E)-geranylacetone. These changes significantly altered the overall aroma profile.

The types of higher alcohols detected in mature grapes from plants with different treatments varied widely (Table 4), with 1- octen-3-ol and isoamyl alcohol detected only in grapes harvested in 2019, and 1,7octadien-3-ol was detected only in 2018. There was an overall increase in higher alcohols under KPF treatment for grapes harvested in 2018, with higher concentrations of 3-hexen-1-ol, 1,7-octadien-3-ol, and 1octanol. However, no obvious differences were detected in 2019 for grapes from treated or untreated plants.

Low amounts of volatile benzene-derivatives were detected in the mature grapes, with $5.46 \%$ (2018 control), 4.96\% (2018 KPF treatment), $5.52 \%$ (2019 control), and 5.17\% (2019 KPF treatment) of the total volatile compounds. For the detected volatile benzene-derivatives, there were three volatile substances with OAV $>1$ : benzeneacetaldehyde, methyl salicylate, 
A

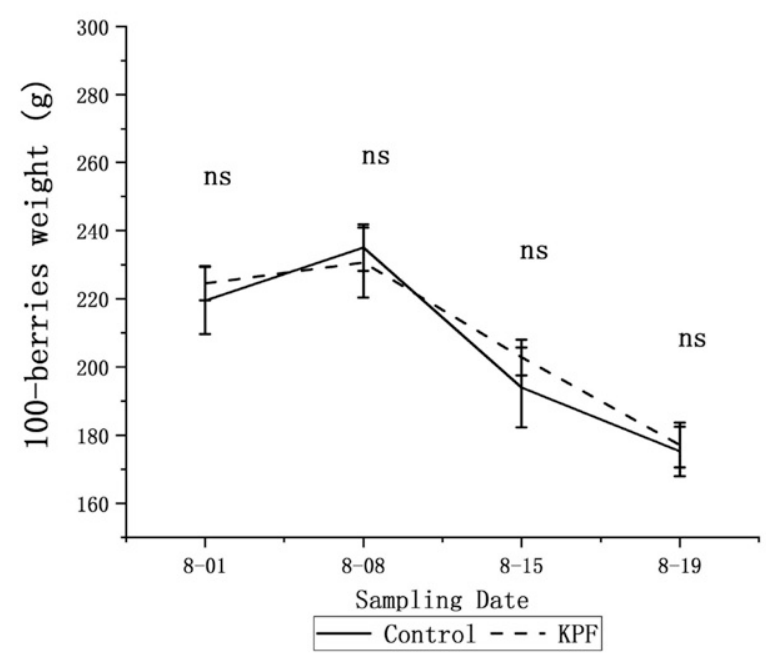

$\mathrm{C}$

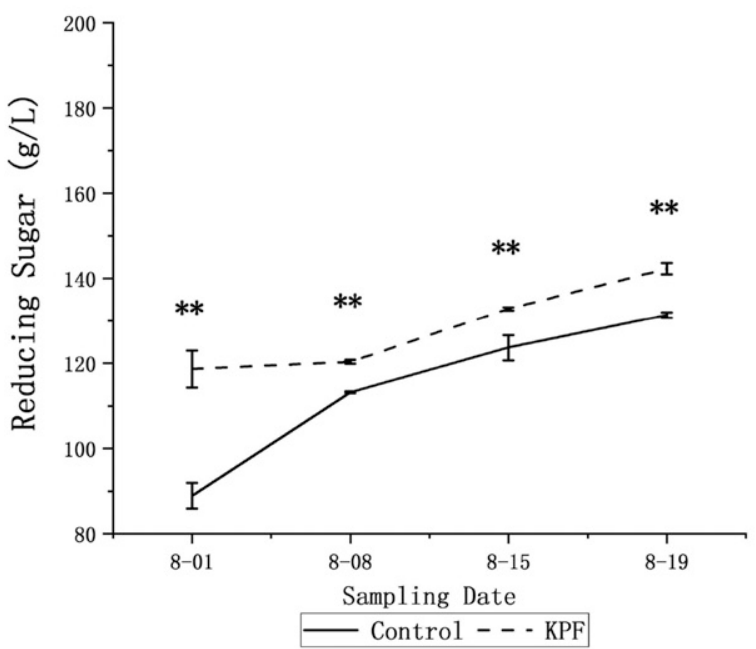

B

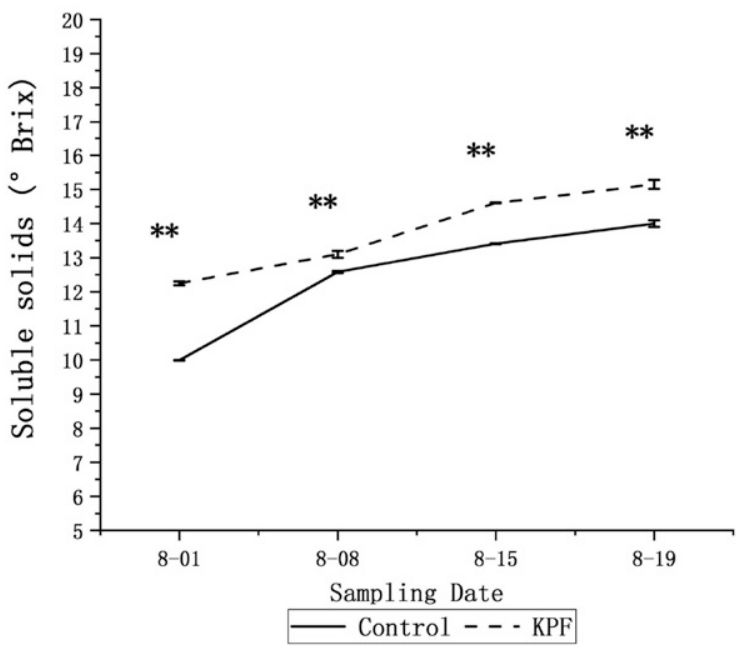

$\mathrm{D}$

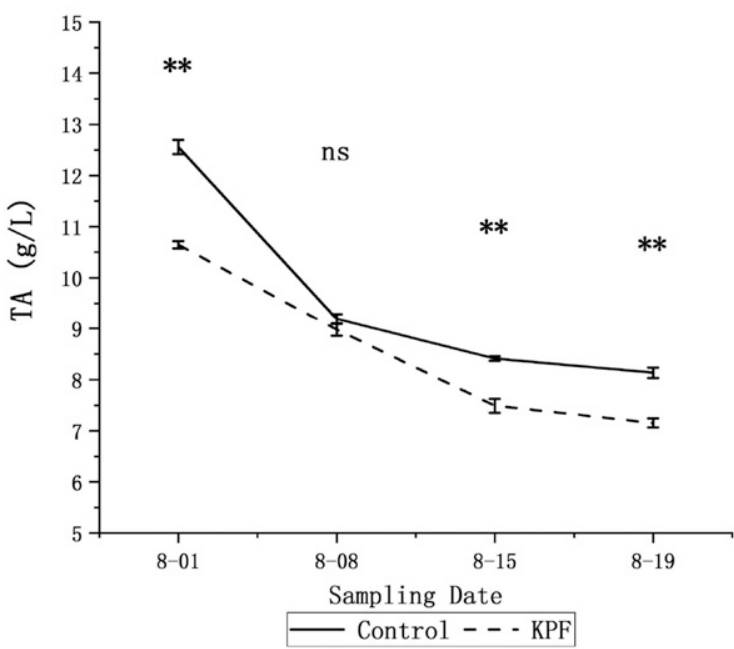

Fig. 3. Effect of kaolin application on the physicochemical indexes of grape berries in 2019. The effect of exogenous kaolin on (A) 100-berries weight, (B) soluble solids (SS), (C) reducing sugar, and (D) titratable acid (TA). Grape berries were collected on five different dates after veraison from vines treated with kaolin particle film (KPF) and without KPF application (control). Values are the mean \pm SEM of four independent experiments. Effects of kaolin were tested by Student's $t$ test. ${ }^{*} P<0.05$ and ${ }^{* *} P<0.01$ represent significant differences between treatments (control and KPF) and NS indicates not significant.

and 2,4-di-tert-butylphenol, which, respectively, provide floral, mint, and chemical smells of phenols. The average OAV of benzeneacetaldehyde was 247.21 , which is well above its threshold of $0.004 \mathrm{mg} / \mathrm{L}$. For the 2018 plants, KPF increased the content of benzeneacetaldehyde, 2,4-di-tert-butylphenol, and benzaldehyde, and reduced the content of styrene and 2,4-dimethyl-benzaldehyde. In 2019, KPF treatment reduced the content of methyl salicylate and 2,4-dimethyl-benzaldehyde, but it had no detectable influence on other volatile benzene-derivatives.

Analysis of the volatile compounds in all grapes revealed that aldehydes were highly abundant, making up greater than $85 \%$ of the total volatile compounds. There was little change with treatment observed in the types of aldehydes and ketones detected, but the concentrations of some aldehydes increased with KPF treatment, including hexanal, (E)2-hexenal, and nonanal for mature grapes harvested in 2018. In mature grapes harvested in 2019, aldehydes and ketones showed no significant changes with treatment, except for a decrease in the amount of 3-nonanone.

Ten esters were detected, and methyl 2methoxybenzoate, ethyl octoate, and ethyl caprate exhibited average OAV $>1$. Significant differences were found in the types of ester compounds in grapes from plants from different treatments. In 2018, ethyl acetate, methyl 2-methoxybenzoate, ethyl octoate, and ethyl dodecanoate were not found in grapes from KPF-treated plants, but these were detected in grapes from untreated plants. A greater variety of ester compounds were detected in mature grapes in 2019 compared with those detected in 2018, in- cluding phenyl butyrate, 2-ethylhexyl trichloroacetate, and citronellyl tiglate. No significant differences were observed in the concentrations of esters in grapes over all treatments, except for increases in formic acid and hexyl ester with KPF treatment in 2018.

Principal component analysis of volatile profiles. To visualize the effects of KPF on grape volatile profiles, principal component analysis (PCA) was performed. Only volatile phenolic compounds with average OAV $>1$ were included in this PCA analysis, and the results are shown in Fig. 8.

The first two PCs accounted for $83.6 \%$ of the variation in the volatile compounds, with PC1 explaining $49.9 \%$ of the variation and $\mathrm{PC} 2$ explaining $33.7 \%$. The PCA of the composition of different samples (Control 2018, KPF 2018, Control 2019, and KPF 
A

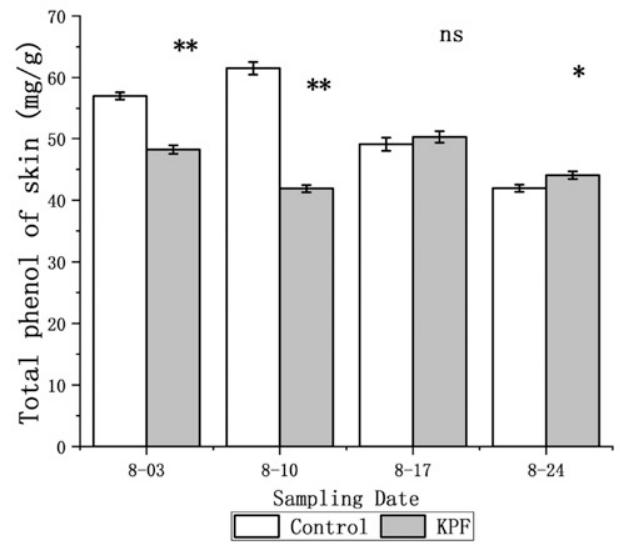

C

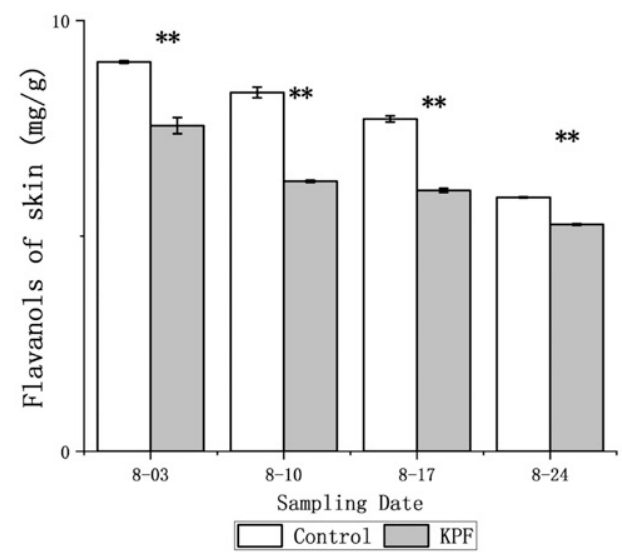

E

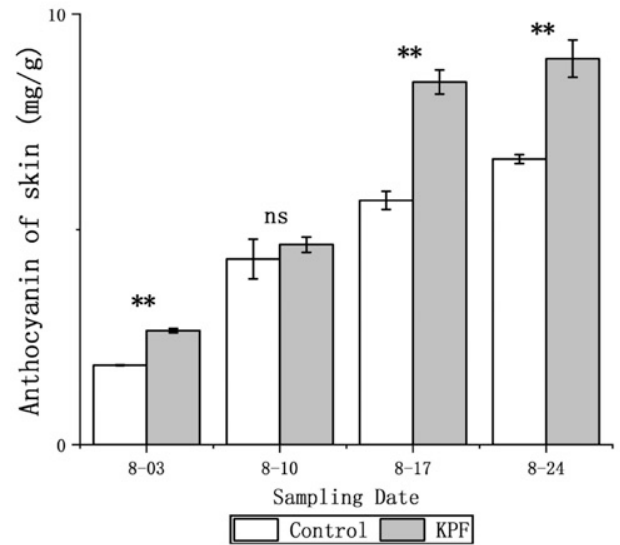

B

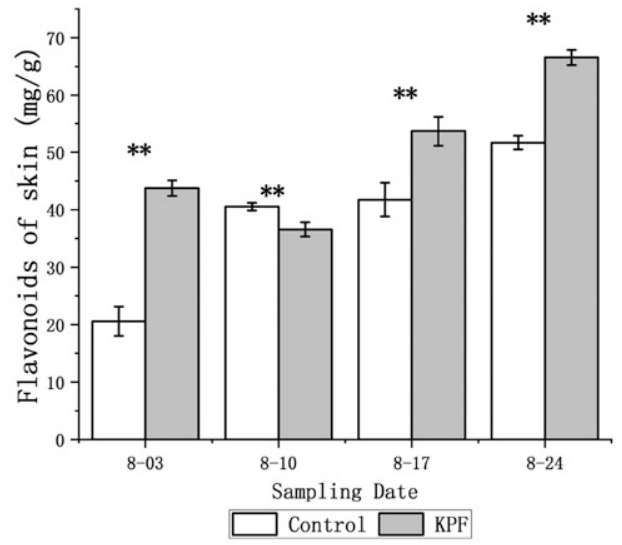

D

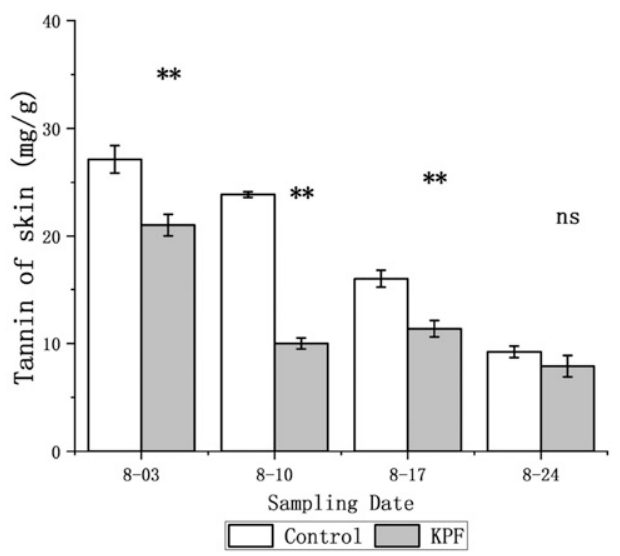


A

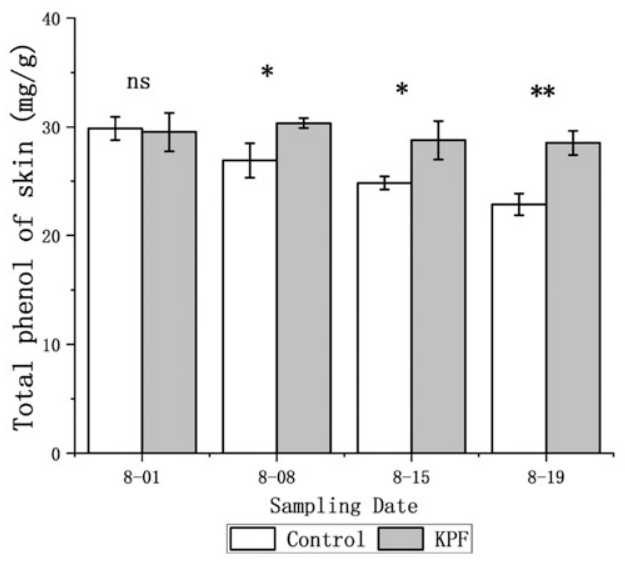

$\mathrm{C}$

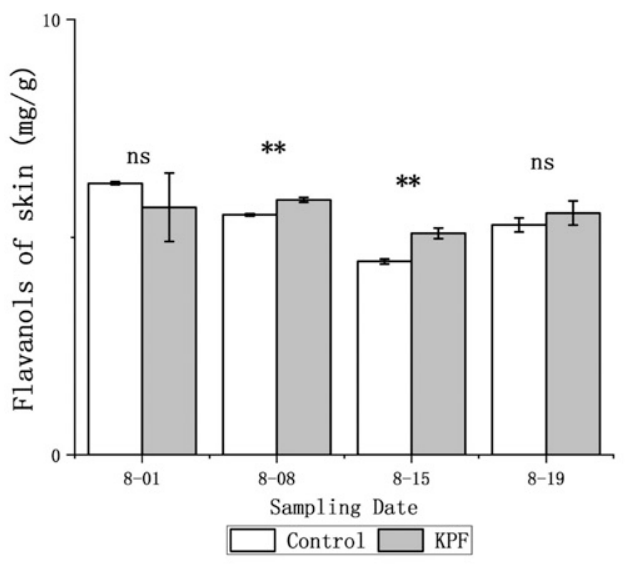

E

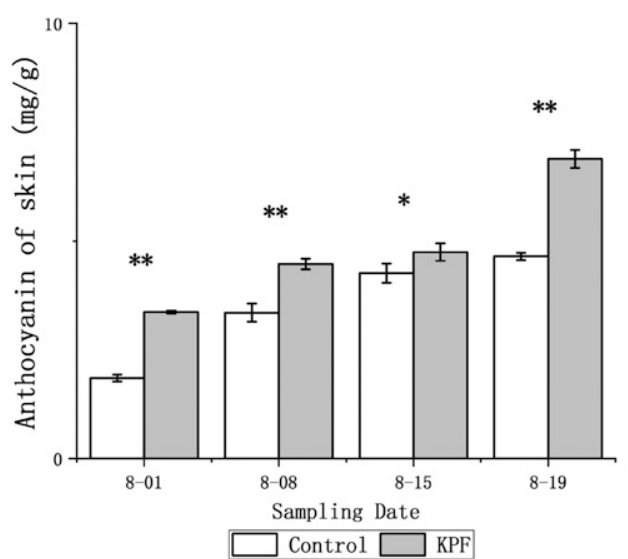

B

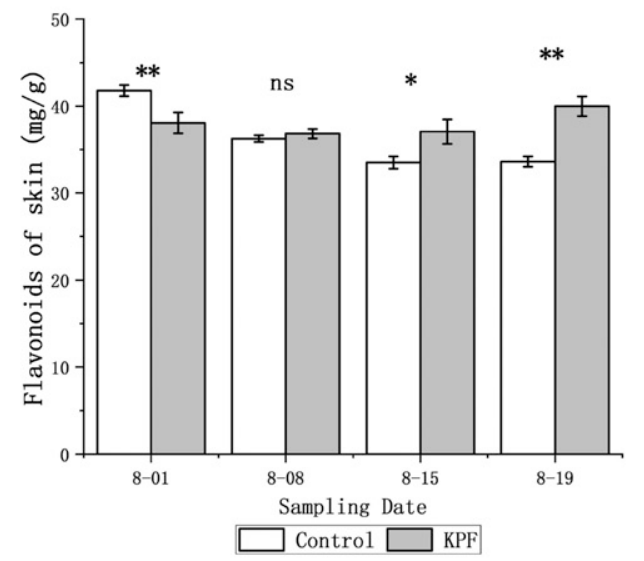

$\mathrm{D}$

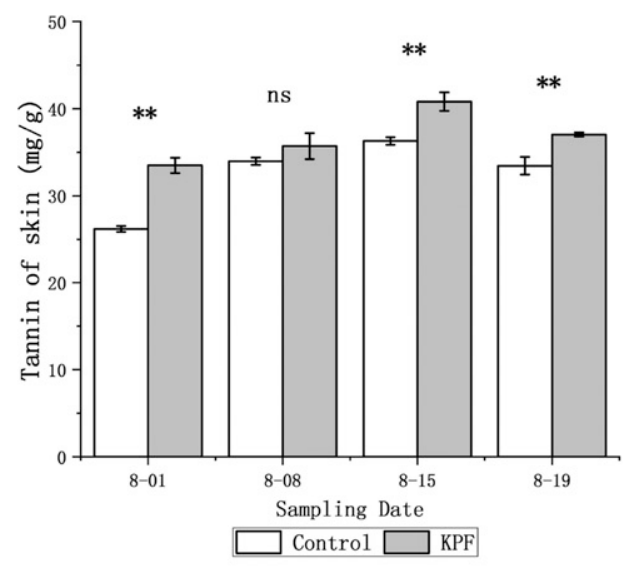

Fig. 5. Effect of kaolin application on the content of polyphenols in grape skins in 2019. The effect of exogenous kaolin on (A) total phenol, (B) flavonoids, (C) flavanol, (D) tannin, and (E) anthocyanins in grape skins. Grape berries were collected on five different dates after veraison from vines treated with kaolin particle film (KPF) and without KPF application (control). Values are the mean \pm SEM of four independent experiments. Effects of kaolin were tested by Student's $t$ test. ${ }^{*} P<0.05$ and ${ }^{* *} P<0.01$ represent significant differences between treatments (control and KPF) and NS indicates not significant.

different vintages. The point for KPF 2018 was in the first quadrant. The compounds positioned in the first quadrant are geranylacetone, nonanal, hexanal, and 2,4-di-tertbutylphenol. These compounds contribute significantly to the aroma of KPF 2018, given their proximity to the point corresponding to KPF 2018, with an aroma of flower and grass. The closest volatile compound to the point corresponding to KPF 2018 was 2,4-di-tertbutylphenol, which contributes to the chemical smell of phenols. This compound would contribute a negative aroma of grapes and wine if present at too high of a concentration (Li, 2006). The point corresponding to KPF 2019 was in the second quadrant, with fewer volatile compounds plotted close to this point, indicating few types and low content 
Table 1. Effect of kaolin application on the ratio of anthocyanins to soluble solids (A/SS) in 2018 .

\begin{tabular}{lccc}
\hline & \multicolumn{2}{c}{ Ratio of anthocyanins to soluble solids (A/SS) } & \\
\cline { 2 - 3 } Sampling date & Control & KPF & Significance $^{\mathrm{y}}$ \\
\hline 3 Aug. & $0.329 \pm 0.036$ & $0.334 \pm 0.013$ & NS \\
10 Aug. & $0.382 \pm 0.013$ & $0.54 \pm 0.017$ & $* *$ \\
17 Aug. & $0.226 \pm 0.004$ & $0.419 \pm 0.002$ & $* *$ \\
24 Aug. & $0.375 \pm 0.006$ & $0.441 \pm 0.025$ & $*$ \\
\hline
\end{tabular}

${ }^{\mathrm{z}}$ Grape berries were collected on four different dates after veraison from vines treated with kaolin particle film (KPF) and without KPF application (control).

${ }^{\mathrm{y}}$ Values are the mean \pm SEM of four independent experiments.

${ }^{\mathrm{x}}$ Effects of kaolin were tested by a Student's $t$ test. ${ }^{*} P<0.05$ and $* * P<0.01$ represent significant differences between treatments (control and KPF) and Ns indicates not significant.

Table 2. Effect of kaolin application on the ratio of anthocyanins to soluble solids (A/SS) in 2019.

\begin{tabular}{|c|c|c|c|}
\hline \multirow[b]{2}{*}{ Sampling date d $^{z}$} & \multicolumn{2}{|c|}{ Ratio of anthocyanins to soluble solids (A/SS) } & \multirow[b]{2}{*}{ Significance $^{\mathrm{x}}$} \\
\hline & Control & $\mathrm{KPF}$ & \\
\hline 1 Aug. & $0.186 \pm 0.008$ & $0.275 \pm 0.003$ & $* *$ \\
\hline 8 Aug. & $0.267 \pm 0.017$ & $0.342 \pm 0.009$ & $* *$ \\
\hline 15 Aug. & $0.305 \pm 0.018$ & $0.314 \pm 0.014$ & NS \\
\hline 19 Aug. & $0.347 \pm 0.006$ & $0.472 \pm 0.015$ & $* *$ \\
\hline
\end{tabular}

${ }^{\mathrm{z}}$ Grape berries were collected on four different dates after veraison from vines treated with kaolin particle film (KPF) and without KPF application (control).

${ }^{\mathrm{y}}$ Values are the mean \pm SEM of four independent experiments.

${ }^{\mathrm{x}}$ Effects of kaolin were tested by a Student's $t$ test. ${ }^{* *} P<0.01$ represents significant differences between treatments (control and KPF) and NS indicates not significant.

of volatile compounds in grapes from KPFtreated plants in 2019. The volatile compounds close to the point corresponding to KPF 2019 were benzeneacetaldehyde, 3hexen-1-ol, and 2-methyl-butanal, which contribute to the aroma of the flower, green leaves and malt, barbecue, respectively. Most of the volatile compounds were positioned in the third quadrant. Most points near the point corresponding to Control 2019 were esters, with a few ketones and aldehydes. Esters can be major contributors to the fruit aroma of grapes. The compounds corresponding to points located close to the point corresponding to Control 2019 can contribute to aromatic notes of flower and fruit, with methyl salicylate also contributing to an aroma of mint and herb (Li, 2006). The point corresponding to Control 2018 was positioned in the fourth quadrant, close to points corresponding to aromatic compounds of decanal, 2-nonanone, 2-octanone, and methyl 2-methoxybenzoate. These compounds contribute to an aroma of plants and flowers.

\section{Discussion}

Many regions where wine grapes are grown in China experience a continental monsoon climate, with rain and heat during the growing season, which can cause disease (Onesti et al., 2017). As discussed in this study, a recently bred wine grape cultivar may be more suitable for this climate, 'Meili' (Vitis vinifera L.), due to its short time of maturation and because it exhibits strong resistance to fungal diseases. However, the amounts of accumulated sugar and phenolic and volatile compounds, important indicators of grape and wine quality, are much lower in this variety than those in more widely cultivated varieties (Peng et al., 2013). Thus, there is strong interest in the development of cultivation practices that could improve the grape and wine quality of this cultivar. The application of KPF was tested with other grape varieties and found to increase the content of primary and secondary metabolites (Conde et al., 2016, 2018; Sharma et al., 2015), so KPF was tested here for its ability to affect the maturation process and metabolism of 'Meili' to evaluate the quality of grape.

KPF influence on grape maturation. The observed increase of SS and reducing sugar in grapes from plants treated with KPF is consistent with previous reports testing other grape varieties (Shellie and Glenn, 2008; Shellie and King, 2013b). Additionally, the TA content was decreased. Because the sugar-to-acid ratio generally is used as an indicator of grape maturation ( $\mathrm{Li}$ et al., 2009), the increased SS and reducing sugar, and decreased TA indicate higher maturation of grapes with the KPF application.

$K P F$ influence on phenolic compounds, including anthocyanin. The levels of phenolic compounds are important indicators of grape fruit quality (Mills et al., 2006). Here, the use of KPF increased the content of most phenolic compounds during the late stage of ripening, including total phenols, flavonoids, flavonol, and anthocyanin in both the skin and seeds of grapes. These results were consistent with the previous finding that KPF treatment increased accumulation of total phenols, flavonoids, and anthocyanins in grapes (Conde et al., 2016). To explore how exogenous KPF treatment can influence secondary metabolism pathways to promote the biosynthesis of phenolics and anthocyanins, molecular and biochemical analyses were performed (Conde et al., 2016). Their results revealed that grapes from treated plants exhibited significantly increased concentrations of several phenolic monomers (quercetin, catechin, and peinidin 3-galactoside), increased key enzymatic activities, and increased expression of genes involved in the key phenolic synthesis pathway.

An increase in the anthocyanin concentration was observed for grapes from plants treated with KPF for all sampling dates. This consistent increase in the anthocyanin level was further investigated by measuring the level of monomeric anthocyanin by HPLC. As shown in Table 3, compared with the control plants, KPF treatment increased total anthocyanins and monomeric anthocyanin, consistent with the results of previous studies (Dinis et al., 2016; Shellie and King, 2013a; Song et al., 2012). The content of anthocyanins in red wine grape skins is an important contributor to grape and wine quality. There are five classes of anthocyanidins present in red grape skins: cyanidin, peonidin, delphindin, petunidin, and malvidin. Delphinidin is the precursor of petunidin and malvidin, and cyanidin is the precursor of peonidin. Cyanidin and peonidin confer red color, and the other three classes of anthocyanidins confer blue color. Thus the relative proportion of these color-determining compounds determines red/purple/blue color variation in grape varieties and their corresponding wines and juices (Castellarin et al., 2006). The amounts of red color and blue color anthocyanins were calculated, and the results are shown in Table 3 . There was a bigger increase in the amounts of delphinidin and derivatives than for cyanidin and derivatives, indicating that KPF treatment changed the ratio of delphinidin- to cyanidin-derived anthocyanins and may result in increased blue color.

Anthocyanins are sensitive to high temperatures. Temperatures above $30{ }^{\circ} \mathrm{C}$ can inhibit anthocyanin accumulation and accelerate anthocyanin degradation (Spayd et al., 2002). Anthocyanin stability depends on structure; and methoxylation, glycosylation, and acylation increase anthocyanin stability (Jackman and Smith, 1996). Malvidin and peonidin derivatives are highly methylated anthocyanins and are more stable than other anthocyanins at a high temperature (Mori et al., 2007). Here, we calculated the content of highly methylated anthocyanidins (peonidin- and malvidin-3-glucoside) and less methylated anthocyanins (delphinidin-, cyanidin-, and petunidin-3-glucoside) in grape skins from control or treated plants, and the results are shown in Table 3. KPF treatment resulted in a greater increase in lowmethylated anthocyanins, which are more sensitive to high temperature, compared with the observed increase in high-methylated anthocyanins. The increase of anthocyanin may be due to the decreased temperature of the canopy and grape surface resulting from KPF treatment, and this lower surface temperature may slow the degradation of anthocyanin (Yamane et al., 2006).

Wine quality requires a balance of color and alcohol, and these characteristics are 
A

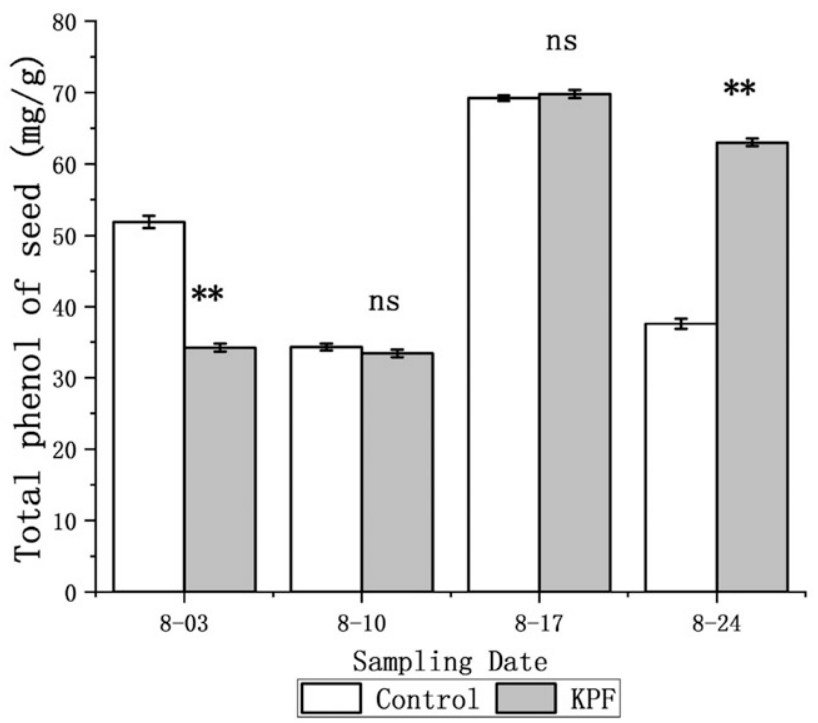

$\mathrm{C}$

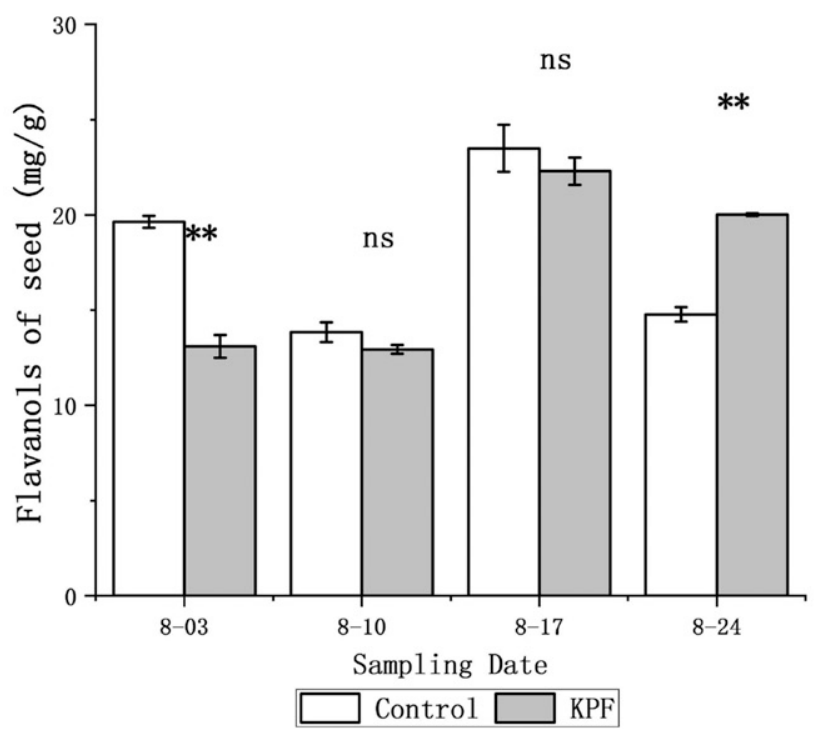

B

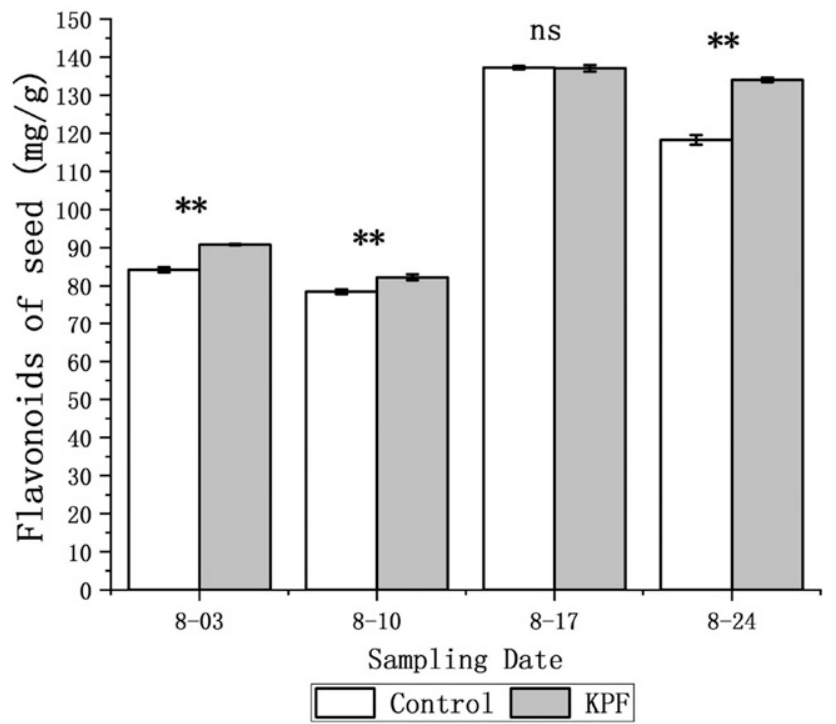

$\mathrm{D}$

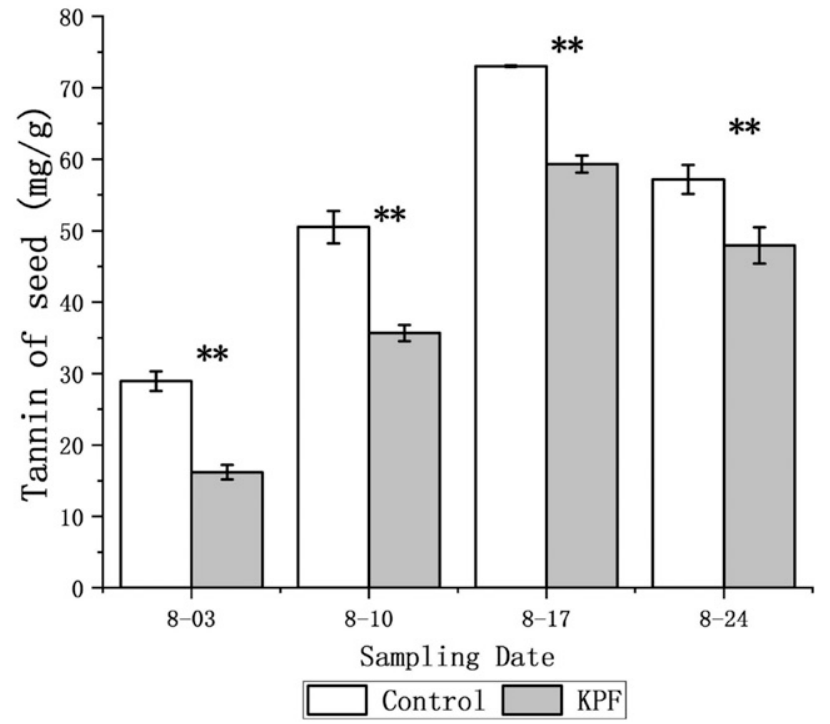

Fig. 6. Effect of kaolin application on the content of polyphenols in grape seeds in 2018. The effect of exogenous kaolin on (A) total phenol, (B) flavonoids, (C) flavanol, and (D) tannin in grape seeds. Grape berries were collected on five different dates after veraison from vines treated with kaolin particle film (KPF) and without KPF application (control). Values are the mean \pm SEM of four independent experiments. Effects of kaolin were tested by Student's $t$ test. * $P<0.05$ and $* * P<0.01$ represent significant differences between treatments (control and KPF) and NS indicates not significant.

affected by the A/SS (Shellie, 2015). A decreased $\mathrm{A} / \mathrm{SS}$ is related to elevated temperature (Sadras and Moran, 2012). In this study, the particle film treatment increased both anthocyanins and soluble solids, suggesting stimulation of both primary and secondary metabolism; but A/SS was higher in treated grape skins, as reported previously (Shellie and King, 2013a). The increased A/ SS with treatment is consistent with an effect of KPF to reduce grape surface temperature. This cooler surface temperature might further affect the balance between primary and secondary metabolism.

Light can also affect anthocyanin content (Kuhn et al., 2014). Although kaolin residue on the surface of grapes can increase the reflection of some light radiation, the observed increased content of anthocyanin in grape skins from treated plants indicates that sufficient light is transmitted to synthesize anthocyanin.

$K P F$ influence on volatile compounds in grapes. Few studies have investigated how the application of foliar particle film during grape development influences the volatile composition of grapes and the resulting wine. Interestingly, previous work found little effect of KPF treatment on volatile composition unless the treatment was combined with deficit irrigation (Ou et al., 2010; Song et al., 2012).

The OAV is a useful index to determine the important aromatic components in a com- plex system (Zhang et al., 2007). In general, volatile compounds that are present at concentrations over their corresponding odor threshold values $(\mathrm{OAV}>1)$ are considered active odorants that can contribute major aroma characteristics (Guth, 1997b). The average OAVs of different compounds were calculated in this study. The four compounds with the highest OAVs were hexanal, nonanal decanal, and octanal, with values much greater than 1, indicating major contributions to aroma. These compounds provide fruity, floral, and grassy aromas.

In general, varietal aroma compounds exit as nonvolatile aroma precursors in grape skins, mainly as aroma glycosides. Aroma 
A

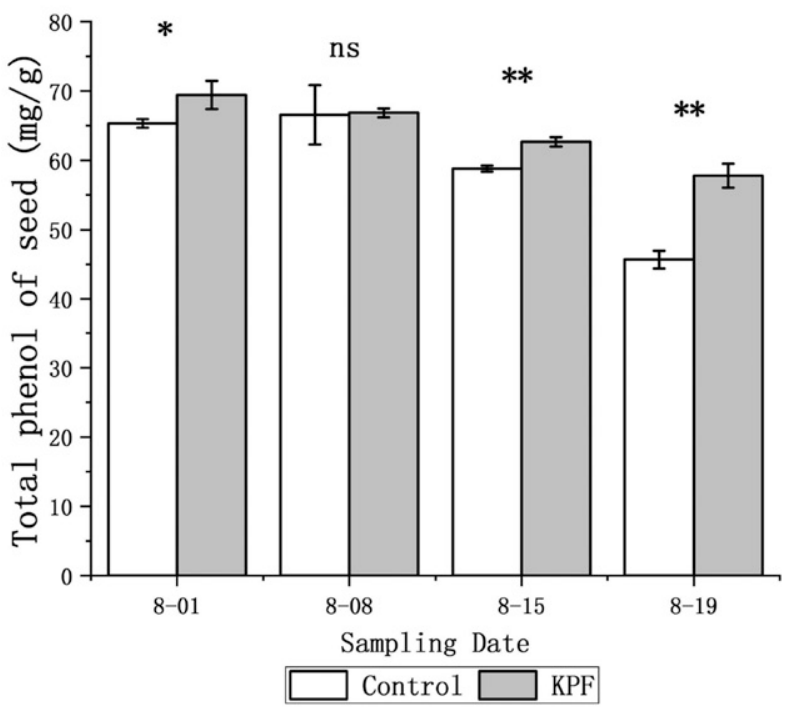

$\mathrm{C}$

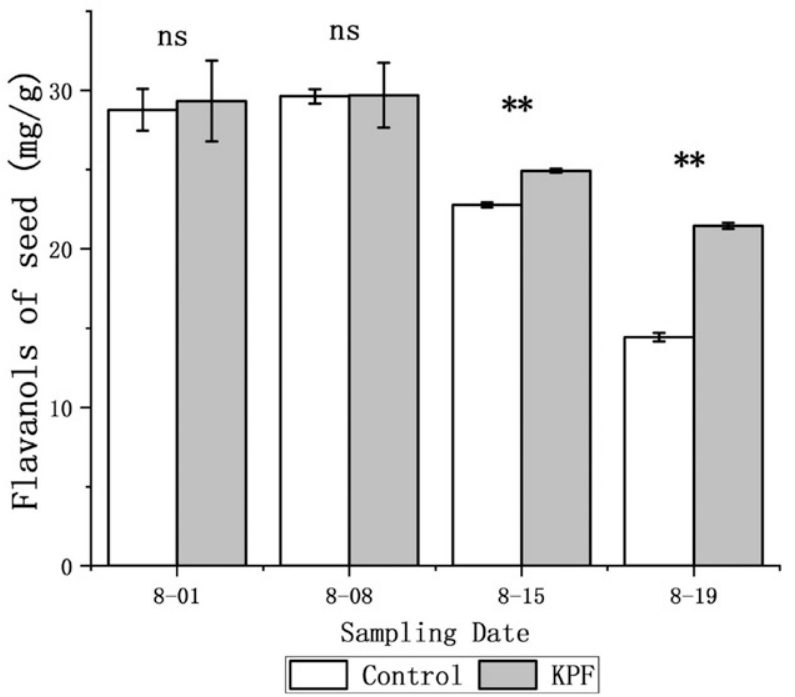

B

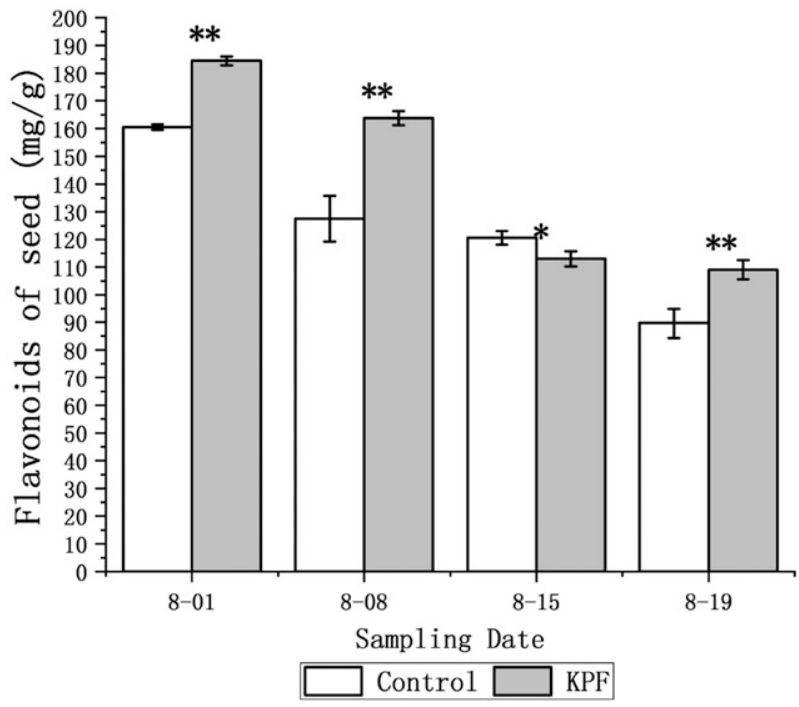

$\mathrm{D}$

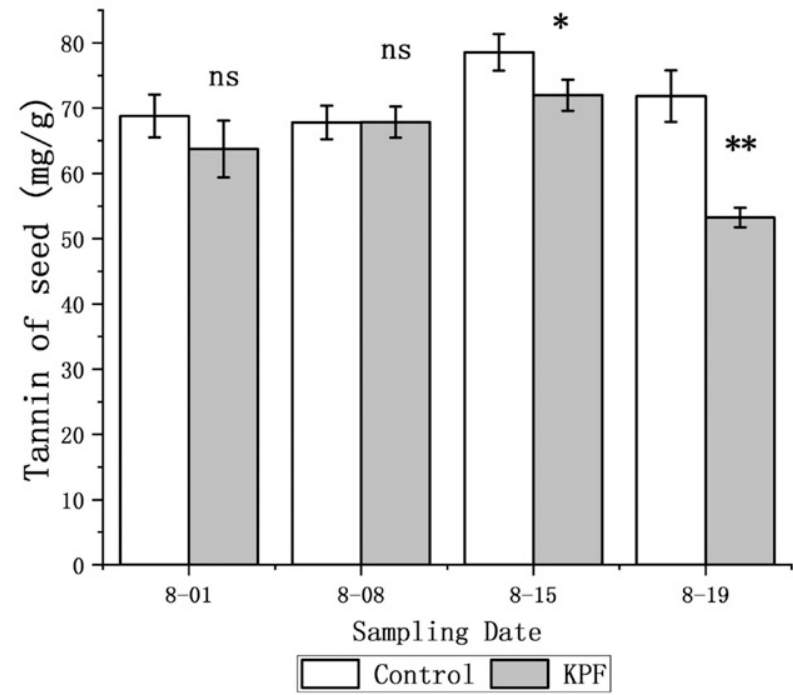

Fig. 7. Effect of kaolin application on the content of polyphenols in grape seeds in 2019. The effect of exogenous kaolin on (A) total phenol, (B) flavonoids, (C) flavanol, and (D) tannin in grape seeds. Grape berries were collected on five different dates after veraison from vines treated with kaolin particle film (KPF) and without KPF application (control). Values are the mean \pm SEM of four independent experiments. Effects of kaolin were tested by Student's $t$ test. * $P<0.05$ and ${ }^{*} P<0.01$ represent significant differences between treatments (control and KPF) and NS indicates not significant.

Table 3. Effect of kaolin application on the content of monomeric anthocyanins in 2018.

\begin{tabular}{|c|c|c|c|c|}
\hline & \multicolumn{2}{|c|}{ Content $(\mathrm{mg} / \mathrm{L})^{\mathrm{z}}$} & \multirow[b]{2}{*}{ Significance $y$} & \multirow[b]{2}{*}{ Increase $(\%)^{x}$} \\
\hline & Control & KPF & & \\
\hline Total monomeric anthocyanins & $84.73 \pm 0.11$ & $114.94 \pm 0.22$ & ** & 35.66 \\
\hline Delphinidin-3-gliucoside & $0.94 \pm 0.00$ & $1.33 \pm 0.01$ & ** & 41.22 \\
\hline Petunidin-3-glucoside & $1.44 \pm 0.01$ & $2.06 \pm 0.02$ & $* *$ & 43.16 \\
\hline Peonidin-3-glucoside & $60.50 \pm 0.05$ & $80.60 \pm 0.17$ & $* *$ & 33.23 \\
\hline Malvidin-3-glucoside & $5.63 \pm 0.01$ & $7.69 \pm 0.04$ & $* *$ & 36.58 \\
\hline Delphinidin and its derivate & $8.01 \pm 0.01$ & $11.08 \pm 0.06$ & ** & 38.30 \\
\hline Low-methylated anthocyanins & $18.57 \pm 0.00$ & $25.84 \pm 0.01$ & ** & 39.15 \\
\hline
\end{tabular}

${ }^{\mathrm{z}}$ Values are the mean \pm SEM of four independent experiments.

${ }^{\mathrm{y}}$ Effects of kaolin were tested by a Student's $t$ test. $* * P<0.01$ represents significant differences between treatments [control and kaolin particle film (KPF)].

${ }^{\mathrm{x}}$ Values are expressed as a percentage increase of KPF treatment relative to the control. 
Table 4. Effect of kaolin particle film (KPF) on volatile compounds in two sampling years.

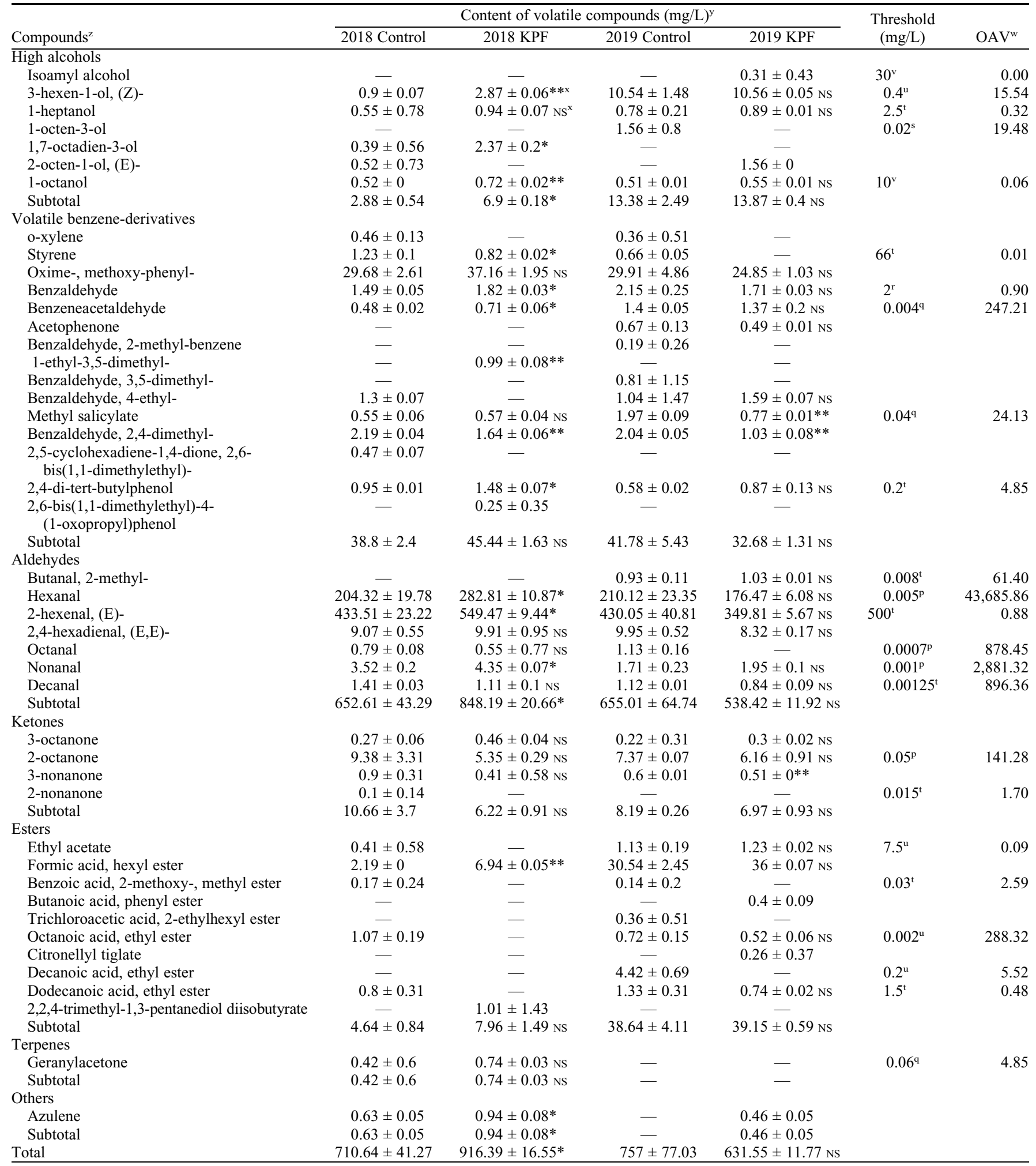

${ }^{\mathrm{z}}$ Grape berries were collected when they matured from vines treated with KPF and without KPF application (control) in two years.

${ }^{\mathrm{y}}$ Values are the mean \pm SEM of four independent experiments.

${ }^{\mathrm{x}}$ Effects of kaolin were tested by a Student's $t$ test each year. $* P<0.05$ and $* * P<0.01$ represent significant differences between treatments (control and KPF) and Ns indicates not significant.

${ }^{\mathrm{w}}$ Odor activity value (OAV) was calculated by the ratio of odor concentration to odor threshold.

${ }^{\mathrm{v}}$ Reference (Moreno et al., 2005).

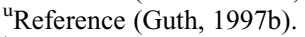

${ }^{\mathrm{t}}$ Reference (Li, 2006).

${ }^{\mathrm{s}}$ Reference (La Guerche et al., 2006).

${ }^{\mathrm{r}}$ Reference (Peinado et al., 2004).

${ }^{\mathrm{q}}$ Reference (Fan et al., 2010).

${ }^{\mathrm{p}}$ Reference (Buttery et al., 1988). 


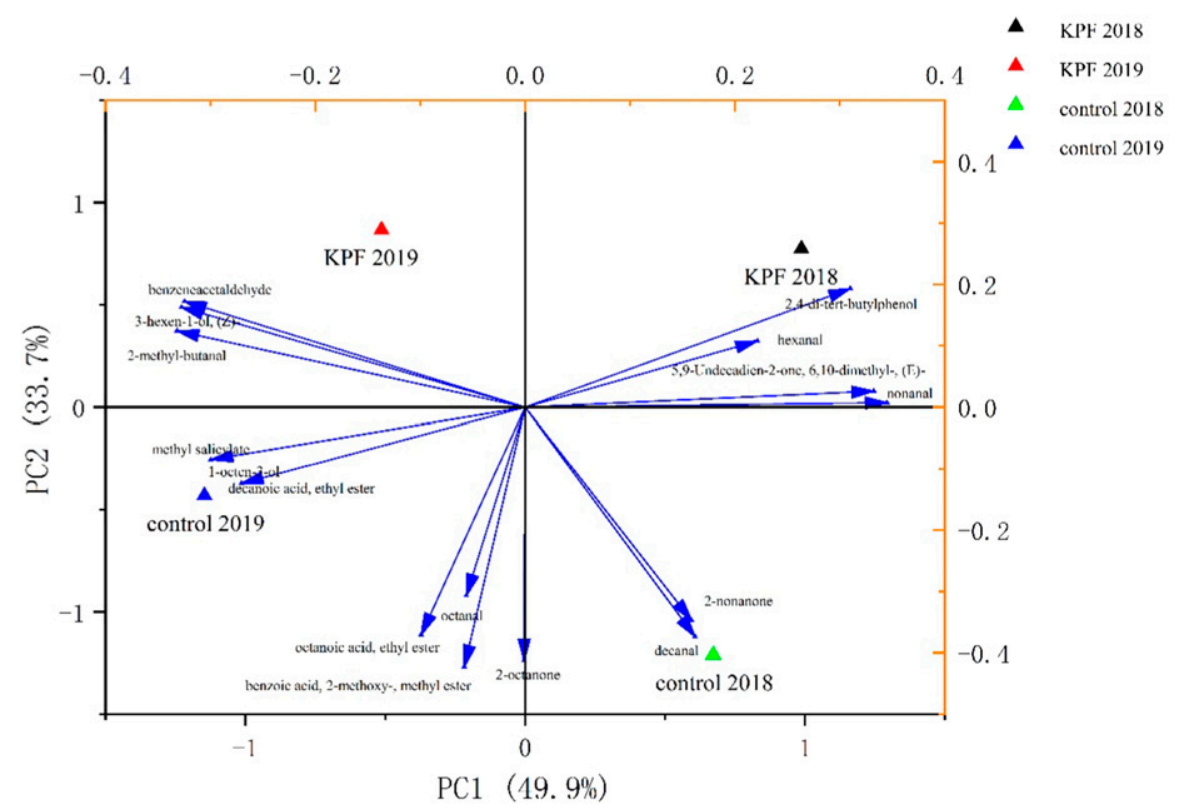

Fig. 8. Principal component analysis (PCA) of volatile compounds of 'Meili' harvested in 2018 and 2019 from vines with or without (Control) foliar application of kaolin particle film. Metabolite profiles of the grape berries were determined using gas-chromatography and mass spectrometry.

glycosides are composed of free aroma and glycosyl moieties, which are linked via glycosidic bond. These aroma precursors, mainly C13-norisoprenoids and terpenes, can be hydrolyzed to free aroma compounds during the wine-making process (Abbott et al., 1991). In this study, only volatile compounds in berries were measured. Terpenes are usually associated with floral and citric aromas (Guth, 1997a), and they are key indicators of the variety and quality of grapes because terpene levels are unaffected by yeast metabolism during fermentation (Begala et al., 2002). Individual terpenoids changed with KPF treatment, but this trend was not consistent for the two years. The terpene geranylacetone was detected at a low concentration in this study, but it may be an important contributor of aroma characteristics because of its low threshold. The most abundant compounds detected here were C6 compounds (hexenal, (E)-2-hexenal, and (Z)3-hexen-1-ol), which usually supply vegetal and herbaceous aromas (Hashizume and Samuta, 1997). The concentrations of these compounds were higher in grapes from KPFtreated plants in 2018, but this trend was not consistent in 2019. Typically, C6 compounds in grapes have a negative influence on the flavor of the resulting wine when their concentration exceeds the odor threshold (Ferreira et al., 1995). In general, a reduction of C6 compounds is associated with fruit maturation (Coelho et al., 2007).

Higher alcohols usually contribute strong and pungent smell and taste, with an herbaceous odor (García-Carpintero et al., 2011). Higher alcohols (Z)-3-hexen-1-ol and 1octen-3-ol were detected at concentrations higher than their corresponding threshold values (OAVs $>1)$; (Z)-3-hexen-1-ol mainly produces the green leaf aroma, and 1-octen- 3-ol mainly contributes lavender and rose aromas. Volatile benzene-derivatives (mainly produced through the shikimate pathway) also contribute to varietal aromas, including floral 2011). Among the detected volatile benzenederivatives, the OAV of benzeneacetaldehyde was far greater than 1, suggesting that benzeneacetaldehyde is an important determinant of aroma in 'Meili' grapes. The concentrations of many aldehydes were well above threshold values, which would provide fruit, rose, grass, and other plant smells. Esters are usually fruity and sweet, and they are considered important contributors to wine aroma (García-Carpintero et al., 2011).

PCA analysis was next performed for compounds with OAV $>1$. The results indicated a greater difference in grapes grown in different years rather than between grapes cultivated with or without KPF treatment, with inconsistent results for the two sample years. The observed difference in grape maturation likely reflects weather differences between the two sample years, because there was less rain in 2018 (Fig. 1), a factor that can cause differences in the wines made from these grapes (Falcão et al., 2007). The influence of KPF on grape aroma could vary with vintage.

\section{Conclusion}

The objective of this study was to evaluate the effects of the use of foliar reflective KPF on grape quality, by evaluating grape maturation and metabolites during the growing season. The results indicated that grapes from vines treated with KPF exhibited increased maturation, reflected by higher sugar and lower acid. The concentrations of secondary metabolites, mainly phenols, were also inand rose scents (García-Carpintero et al., creased. The increased anthocyanin and increased ratio of anthocyanin to SS may be related to a decrease in surface temperatures. KPF treatment changed the relative proportion of monomeric anthocyanin, but there was little effect on volatile compounds. Previous studies that showed increased levels of metabolites in plants treated with KPF were conducted in arid and high-temperature areas (Brillante et al., 2016; Conde et al., 2016; Shellie, 2013, 2015; Shellie and Glenn, 2008; Shellie and King, 2013b), which may explain the differences in the results. The observed increases in sugar and phenolic contents indicate that KPF can work under humid climate conditions and suggest that the use of $\mathrm{KPF}$ can improve the quality of the wine grape cultivar Meili.

\section{Literature Cited}

Abbott, N., B. Coombe, and P. Williams. 1991. The contribution of hydrolyzed flavor precursors to quality differences in Shiraz juice and wines: An investigation by sensory descriptive analysis. Amer. J. Enol. Viticult. 42:167-174, doi: 10.1016/S0065-2164(08)70455-6.

Begala, M., L. Corda, G. Podda, M.A. Fedrigo, and P. Traldi. 2002. Headspace solid-phase microextraction gas chromatography/mass spectrometry in the analysis of the aroma constituents of 'Cannonau of Jerzu' wine. Rapid Commun. Mass Spectrom. 16:1086-1091, doi: 10.1002/ rcm.675.

Bernardo, S., L.T. Dinis, A. Luzio, G. Pinto, M. Meijón, L. Valledor, A. Conde, H. Gerós, C.M. Correia, and J. Moutinho-Pereira. 2017. Kaolin particle film application lowers oxidative damage and DNA methylation on grapevine (Vitis vinifera L.). Environ. Expt. Bot. 139:39-47, doi: 10.1016/j.envexpbot.2017.04.002.

Brillante, L., N. Belfiore, F. Gaiotti, L. Lovat, L. Sansone, S. Poni, and D. Tomasi. 2016. Comparing kaolin and pinolene to improve sustainable grapevine production during drought. PLoS One 11:e0156631, doi: 10.1371/ journal.pone.0156631.

Buttery, R.G., J.G. Turnbaugh, and L.C. Ling. 1988. Contribution of volatiles to rice aroma. J. Agr. Food Chem. 36:1006-1009, doi: 10.1021/ jf00083a025.

Canals, R., M.C. Llaudy, J. Valls, J.M. Canals, and F. Zamora. 2005. Influence of ethanol concentration on the extraction of color and phenolic compounds from the skin and seeds of Tempranillo grapes at different stages of ripening. J. Agr. Food Chem. 53:4019-4025, doi: 10.1021/ jf047872v.

Castellarin, S.D., G.D. Gaspero, R. Marconi, A. Nonis, E. Peterlunger, S. Paillard, A.F. AdamBlondon, and R. Testolin. 2006. Colour variation in red grapevines (Vitis vinifera L.): Genomic organisation, expression of flavonoid 3' -hydroxylase, flavonoid $3{ }^{\prime}, 5^{\prime}$-hydroxylase genes and related metabolite profiling of red cyanidin- $/$ blue delphinidin-based anthocyanins in berry skin. BMC Genomics 7(12), doi: 10.1186/14712164-7-12.

Coelho, E., S.M. Rocha, A.S. Barros, I. Delgadillo, and M.A. Coimbra. 2007. Screening of varietyand pre-fermentation-related volatile compounds during ripening of white grapes to define their evolution profile. Anal. Chim. Acta 597:257264, doi: 10.1016/j.aca.2007.07.010

Conde, A., A. Neves, R. Breia, D. Pimentel, L. Dinis, S. Bernardo, C.M. Correia, A. Cunha, H. Geros, and J. Moutinhopereira. 2018. Kaolin 
particle film application stimulates photoassimilate synthesis and modifies the primary metabolome of grape leaves. J. Plant Physiol. 223:47-56, doi: 10.1016/j.jplph.2018.02.004.

Conde, A., D. Pimentel, A. Neves, L. Dinis, S. Bernardo, C.M. Correia, H. Geros, and J. Moutinhopereira. 2016. Kaolin foliar application has a stimulatory effect on phenylpropanoid and flavonoid pathways in grape berries. Front. Plant Sci. 7:1150, doi: 10.3389/fpls. 2016.01150.

Dinis, L.-T., A.C. Malheiro, A. Luzio, H. Fraga, H. Ferreira, I. Gonçalves, G. Pinto, C.M. Correia, and J. Moutinho-Pereira. 2017. Improvement of grapevine physiology and yield under summer stress by kaolin-foliar application: Water relations, photosynthesis and oxidative damage. Photosynthetica 56:641-651, doi: 10.1007/ s11099-017-0714-3.

Dinis, L.-T., S. Bernardo, A. Conde, D. Pimentel, H. Ferreira, L. Félix, H. Gerós, C.M. Correia, and J. Moutinho-Pereira. 2016. Kaolin exogenous application boosts antioxidant capacity and phenolic content in berries and leaves of grapevine under summer stress. J. Plant Physiol. 191:45-53, doi: 10.1016/j.jplph.2015. 12.005 .

Dinis, L.-T., S. Bernardo, A. Luzio, G. Pinto, M. Meijón, M. Pintó-Marijuan, A. Cotado, C. Correia, and J. Moutinho-Pereira. 2018. Kaolin modulates ABA and IAA dynamics and physiology of grapevine under Mediterranean summer stress. J. Plant Physiol. 220:181-192, doi: 10.1016/j.jplph.2017.11.007.

Falcão, L.D., G. de Revel, M.C. Perello, A. Moutsiou, M.C. Zanus, and M.T. BordignonLuiz. 2007. A survey of seasonal temperatures and vineyard altitude influences on 2-methoxy3-isobutylpyrazine, C13-norisoprenoids, and the sensory profile of Brazilian Cabernet Sauvignon wines. J. Agr. Food Chem. 55:36053612, doi: 10.1021/jf070185u.

Fan, W., X. Yan, W. Jiang, and J. Li. 2010. Identification and quantification of impact aroma compounds in 4 nonfloral Vitis vinifera varieties grapes. J. Food Sci. 75:S81-S88, doi: 10.1111/j.1750-3841.2009.01436.x.

Ferrari, V., E. Disegna, E. Dellacassa, and A. Coniberti. 2017. Influence of timing and intensity of fruit zone leaf removal and kaolin applications on bunch rot control and quality improvement of Sauvignon blanc grapes, and wines, in a temperate humid climate. Scientia Hort. 223:62-71, doi: 10.1016/j.scienta.2017. 05.034 .

Ferreira, V., P. Fernández, C. Peña, A. Escudero, and J.F. Cacho. 1995. Investigation on the role played by fermentation esters in the aroma of young Spanish wines by multivariate analysis. J. Sci. Food Agr. 67:381-392, doi: 10.1002/jsfa. 2740670316.

García-Carpintero, E.G., E. Sánchez-Palomo, and M. González-Viñas. 2011. Aroma characterization of red wines from cv. Bobal grape variety grown in La Mancha region. Food Res. Intl. 44:61-70, doi: 10.1016/j.foodres. 2010.11.013.

Glenn, D.M., E. Prado, A. Erez, J.R. Mcferson, and G.J. Puterka. 2002. A reflective, processedkaolin particle film affects fruit temperature, radiation reflection, and solar injury in apple. J. Amer. Soc. Hort. Sci. 127:188-193, doi: 10.21273/JASHS.127.2.188.

Glenn, D.M. and G.J. Puterka. 2010. Particle films: A new technology for agriculture, p. 1-44. In: J. Janick (ed.). Horticulture reviews. vol. 31. Wiley, Hoboken, NJ. doi: 10.1002/ 9780470650882.ch1.
Guth, H. 1997a. Identification of character impact odorants of different white wine varieties. J. Agr. Food Chem. 45:3022-3026, doi: 10.1021/ jf9608433.

Guth, H. 1997b. Quantitation and sensory studies of character impact odorants of different white wine varieties. J. Agr. Food Chem. 45:30273032, doi: 10.1021/jf970280a.

Hashizume, K. and T. Samuta. 1997. Green odorants of grape cluster stem and their ability to cause a wine stemmy flavor. J. Agr. Food Chem. 45:1333-1337, doi: 10.1021/jf960635a.

Jackman, R.L. and J.L. Smith. 1996. Anthocyanins and betalains, p. 244-309. In: G.A.F. Hendry and J.D. Houghton (eds.). Natural food colorants. Springer, Boston, MA. doi: 10.1007/9781-4615-2155-6_8.

Jayaprakasha, G.K., R.P. Singh, and K.K. Sakariah. 2001. Antioxidant activity of grape seed (Vitis vinifera) extracts on peroxidation models in vitro. Food Chem. 73:285-290, doi: 10.1016/S0308-8146(00)00298-3.

Kontoudakis, N., M. Esteruelas, F. Fort, J.M. Canals, V. De Freitas, and F. Zamora. 2011. Influence of the heterogeneity of grape phenolic maturation on wine composition and quality. Food Chem. 124:767-774, doi: 10.1016/ j.foodchem.2010.06.093.

Kuhn, N., L. Guan, Z.W. Dai, B.H. Wu, V. Lauvergeat, E. Gomès, S.H. Li, F. Godoy, P. Arce-Johnson, and S. Delrot. 2014. Berry ripening: Recently heard through the grapevine. J. Expt. Bot. 65:4543-4559, doi: $10.1093 / \mathrm{jxb} /$ ert395.

La Guerche, S., B. Dauphin, M. Pons, D. Blancard, and P. Darriet. 2006. Characterization of some mushroom and earthy off-odors microbially induced by the development of rot on grapes. J. Agr. Food Chem. 54:9193-9200, doi: 10.1021/jf0615294.

Lee, J., R.W. Durst, and R.E. Wrolstad. 2005. Determination of total monomeric anthocyanin pigment content of fruit juices, beverages, natural colorants, and wines by the $\mathrm{pH}$ differential method: Collaborative study. J. AOAC Intl. 88:1269-1278, doi: 10.1093/jaoac/88.5.1269.

Li, H. 2006. Wine tasting, p. 29-106. China Science Press, Beijing, China.

Li, Y.G., G. Tanner, and P. Larkin. 1996. The DMACA-HCl protocol and the threshold proanthocyanidin content for bloat safety in forage legumes. J. Sci. Food Agr. 70(1):89101, doi: 10.1002/(sici)1097-0010(199601) 70:1<89:aid-jsfa470>3.0.co;2-n.

Li, H., Y.J. Wang, J. Meng, H. Wang, J. You, X.S. Huo, and Y.Q. Wang. 2009. The effect of climate change on the climatic zoning for wine grapes in China. Acta Hort. Sinica 36:313-320.

Marinova, D., F. Ribarova, and M. Atanassova. 2005. Total phenolics and flavonoids in Bulgarian fruits and vegetables. J. Univ. Chem. Technol. Metallurgy 40(3):255-260.

Mills, L.J., J.C. Ferguson, and M. Keller. 2006. Cold-hardiness evaluation of grapevine buds and cane tissues. Amer. J. Enol. Viticult. 57:194 200, doi:10.1016/j.scienta.2005.07.007.

Moreno, J.A., L. Zea, L. Moyano, and M. Medina. 2005. Aroma compounds as markers of the changes in sherry wines subjected to biological ageing. Food Control 16:333-338, doi: 10.1016/ j.foodcont.2004.03.013.

Mori, K., N. Goto-Yamamoto, M. Kitayama, and K. Hashizume. 2007. Loss of anthocyanins in red-wine grape under high temperature. J. Expt. Bot. 58:1935-1945, doi: 10.1093/jxb/erm055.

Nicolosi, E., A. Continella, A. Gentile, A. Cicala, and F. Ferlito. 2012. Influence of early leaf removal on autochthonous and international grapevines in Sicily. Scientia Hort. 146:1-6, doi: 10.1016/j.scienta.2012.07.033

Onesti, G., E. Gonzalezdominguez, and V. Rossi. 2017. Production of pycnidia and conidia by guignardia bidwellii, the causal agent of grape black rot, as affected by temperature and humidity. Phytopathology 107:173-183, doi: 10.1094/ PHYTO-07-16-0255-R

Ou, C., X. Du, K. Shellie, C. Ross, and M.C. Qian. 2010. Volatile compounds and sensory attributes of wine from cv. Merlot (Vitis vinifera L.) grown under differential levels of water deficit with or without a kaolin-based, foliar reflectant particle film. J. Agr. Food Chem. 58:12890 12898, doi: 10.1021/jf102587x.

Palomo, E.S., M. González-Viñas, M. Díaz-Maroto, A. Soriano-Pérez, and M. Pérez-Coello. 2007. Aroma potential of Albillo wines and effect of skin-contact treatment. Food Chem. 103: 631-640, doi: 10.1016/j.foodchem.2006. 08.033 .

Peinado, R.A., J. Moreno, J.E. Bueno, J.A. Moreno, and J.C. Mauricio. 2004. Comparative study of aromatic compounds in two young white wines subjected to pre-fermentative cryomaceration. Food Chem. 84:585-590, doi: 10.1016/S03088146(03)00282-6.

Peng, C.-T., Y. Wen, Y.-S. Tao, and Y.-Y. Lan. 2013. Modulating the formation of Meili wine aroma by prefermentative freezing process. J. Agr. Food Chem. 61:1542-1553, doi: 10.1021/ jf3043874.

Roubelakis-Angelakis, K.A. (ed.) 2009. Grapevine molecular physiology \& biotechnology. Springer Science \& Business Media. doi: 10.1007/978-90481-2305-6.

Sadras, V.O. and M.A. Moran. 2012. Elevated temperature decouples anthocyanins and sugars in berries of Shiraz and Cabernet Franc. Austral. J. Grape Wine Res. 18:115-122, doi: 10.1111/ j.1755-0238.2012.00180.

Sarneckis, C.J., R.G. Dambergs, P. Jones, M. Mercurio, M.J. Herderich, and P.A. Smith. 2010. Quantification of condensed tannins by precipitation with methyl cellulose: Development and validation of an optimised tool for grape and wine analysis. Austral. J. Grape Wine Res. 12:39-49, doi: 10.1111/j.17550238.2006.tb00042.x.

Seddon, T.J. and M.O. Downey. 2010. Comparison of analytical methods for the determination of condensed tannins in grape skin. Austral. J. Grape Wine Res. 14:54-61, doi: 10.1111/ j.1755-0238.2008.00007.x.

Sharma, R.R., S.V.R. Reddy, and S.C. Datta. 2015. Particle films and their applications in horticultural crops. Appl. Clay Sci. 116:54-68, doi: 10.1016/j.clay.2015.08.009.

Shellie, K.C. 2006. Vine and berry response of merlot (Vitis vinifera L.) to differential water stress. Amer. J. Enol. Viticult. 57:514-518, doi: 10.1016/j.scienta.2005.07.007.

Shellie, K.C. 2015. Foliar reflective film and water deficit increase anthocyanin to soluble solids ratio during berry ripening in Merlot. Amer. J. Enol. Viticult. 66:348-356, doi: 10.5344/ ajev.2015.14121.

Shellie, K.C. and D.M. Glenn. 2008. Wine grape response to foliar particle film under differing levels of preveraison water stress. HortScience 43:1392-1397, doi: 10.1007/s10658008-9272-7.

Shellie, K.C. and B.A. King. 2013a. Kaolin-based foliar reflectant and water deficit influence Malbec leaf and berry temperature, pigments, and photosynthesis. Amer. J. Enol. Viticult. doi: 10.5344/ajev.2012.12115. 
Shellie, K.C. and B.A. King. 2013b. Kaolin particle film and water deficit influence red winegrape color under high solar radiation in an arid climate. Amer. J. Enol. Viticult. 64:214-222, doi: 10.5344/ajev.2013.12067.

Song, J.-Q., H. Li, Y.-Y. Liang, Y.-S. Tao, C.-Q. Mi, M.C. Qian, and H. Wang. 2013. Characterisation of volatile components of red and sparkling wines from a new wine grape cultivar 'Meili' (Vitis vinifera L.). Vitis 52:41-48, doi: 0042-7500.

Song, J., K.C. Shellie, H. Wang, and M.C. Qian. 2012. Influence of deficit irrigation and kaolin particle film on grape composition and volatile compounds in
Merlot grape (Vitis vinifera L.). Food Chem. 134:841-850, doi: 10.1016/j.foodchem.2012.02.193. Spayd, S.E., J.M. Tarara, D.L. Mee, and J.C. Ferguson. 2002. Separation of sunlight and temperature effects on the composition of Vitis vinifera cv. Merlot Berries. Amer. J. Enol. Viticult. 53:171-182, doi: 10.1021/jf0108664.

Xue, T., X. Han, H. Zhang, Y. Wang, H. Wang, and H. Li. 2019. Effects of a biodegradable liquid film on winter chill protection of winegrape cultivars. Scientia Horticulturae 246:398-406, doi: 10.1016/j.scienta.2018.11.013.

Yamane, T., S.T. Jeong, N. Goto-Yamamoto, Y. Koshita, and S. Kobayashi. 2006. Effects of temperature on anthocyanin biosynthesis in grape berry skins. Amer. J. Enol. Viticult. 57: 54-59.

Zhang, M., Q. Xu, C. Duan, W. Qu, and Y. Wu. 2007. Comparative study of aromatic compounds in young red wines from Cabernet Sauvignon, Cabernet Franc, and Cabernet Gernischet varieties in China. J. Food Sci. 72:C248-C252, doi: 10.1111/j.1750-3841.2007. 00357.x.

Zhang, Z.W., W. Hua, Y.L. Fang, X.I. Zhu-Mei, and Li Hua. 2013. A new high quality winegrape cultivar Meili with disease resistance. Acta Hort. Sinica 40:1611-1612. 